\title{
Fetoplacental Vascular Endothelial Dysfunction as an Early Phenomenon in the Programming of Human Adult Diseases in Subjects Born from Gestational Diabetes Mellitus or Obesity in Pregnancy
}

\author{
Andrea Leiva, ${ }^{1}$ Fabián Pardo, ${ }^{1}$ Marco A. Ramírez, ${ }^{1,2}$ Marcelo Farías, ${ }^{1}$ \\ Paola Casanello, ${ }^{1}$ and Luis Sobrevia ${ }^{1}$ \\ ${ }^{1}$ Cellular and Molecular Physiology Laboratory (CMPL) and Perinatology Research Laboratory (PRL), Division of Obstetrics and \\ Gynaecology, School of Medicine, Faculty of Medicine, Pontificia Universidad Catolica de Chile, P.O. Box 114-D, Santiago, Chile \\ ${ }^{2}$ Biomedical Department, Faculty of Health Sciences, Universidad de Antofagasta, Antofagasta, Chile
}

Correspondence should be addressed to Luis Sobrevia, sobrevia@me.com

Received 16 June 2011; Revised 11 August 2011; Accepted 7 September 2011

Academic Editor: Susan Ozanne

Copyright (C) 2011 Andrea Leiva et al. This is an open access article distributed under the Creative Commons Attribution License, which permits unrestricted use, distribution, and reproduction in any medium, provided the original work is properly cited.

Gestational diabetes mellitus (GDM) and obesity in pregnancy (OP) are pathological conditions associated with placenta vascular dysfunction coursing with metabolic changes at the fetoplacental microvascular and macrovascular endothelium. These alterations are seen as abnormal expression and activity of the cationic amino acid transporters and endothelial nitric oxide synthase isoform, that is, the "endothelial L-arginine/nitric oxide signalling pathway." Several studies suggest that the endogenous nucleoside adenosine along with insulin, and potentially arginases, are factors involved in GDM-, but much less information regards their role in OP-associated placental vascular alterations. There is convincing evidence that GDM and OP prone placental endothelium to an "altered metabolic state" leading to fetal programming evidenced at birth, a phenomenon associated with future development of chronic diseases. In this paper it is suggested that this pathological state could be considered as a metabolic marker that could predict occurrence of diseases in adulthood, such as cardiovascular disease, obesity, diabetes mellitus (including gestational diabetes), and metabolic syndrome.

\section{Introduction}

Pregnancy is a physiological state with a complex anatomical and functional interaction between mother and fetus [1]. When this interaction is not a success, the mother, the fetus, or both exhibit functional impairments. Complications of pregnancy are important causes of maternal mortality, where gestational diabetes mellitus (GDM) and obesity of the mother in pregnancy $(\mathrm{OP})$ are major obstetric pathologies. Fetal-maternal interaction could result in metabolic disturbances leading, for example, to placental and endothelial dysfunction $[2,3]$. Endothelial dysfunction is defined as an altered capacity of the endothelium to take up and metabolize the cationic amino acid L-arginine, the substrate for nitric oxide (NO) synthesis via NO synthases (NOS) $[4,5]$. Interestingly, it is reported that GDM and OP are pathological conditions associated with altered L-arginine transport and $\mathrm{NO}$ synthesis (i.e., the "L-arginine/NO signalling pathway"), probably due to altered uptake and metabolism of adenosine $[6,7]$, an endogenous nucleoside acting as vasodilator in most vascular beds $[8,9]$. These pathophysiological characteristics are considered key in the establishment of a "programmed state" of the developing fetus (i.e., "fetal programming"). This concept refers to the impact of abnormal intrauterine conditions on the development of diseases in adulthood and becomes a key mechanism associated with future development of chronic diseases including cardiovascular disease (CVD), diabetes mellitus, and metabolic syndrome (a concept globalizing clinical association of obesity, type II or non-insulin-dependent diabetes mellitus, hypertension, and dyslipidaemia) [10-12]. Interestingly, GDM is a condition that also increases the risk 


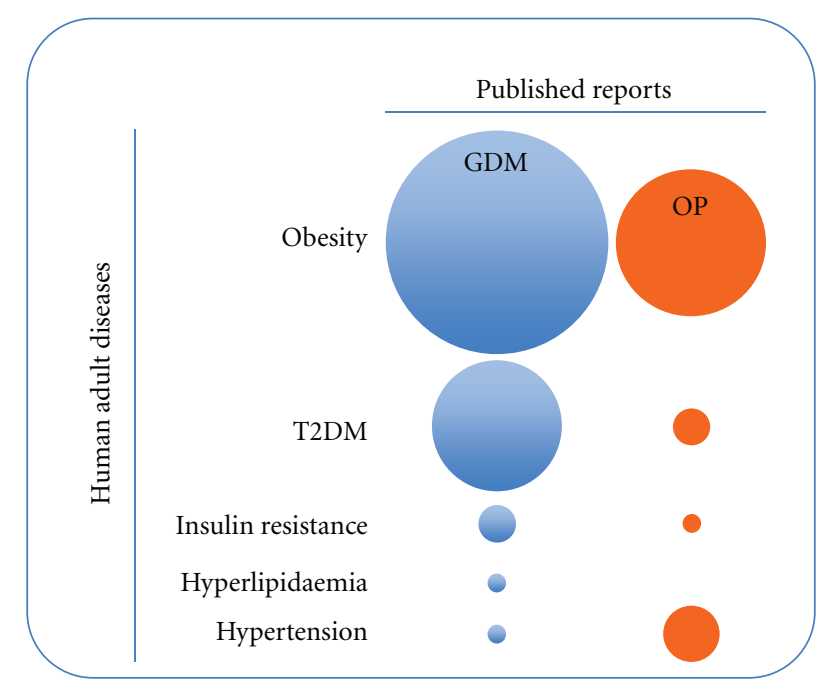

FIgURE 1: Comparison of published reports addressing a potential association of human adult diseases in subjects from pregnancies coursing with gestational diabetes mellitus or obesity in pregnancy. Gestational diabetes mellitus (GDM, column of light-blue circles) and obesity in pregnancy (OP, column of orange circles) are pathological conditions in human subjects. Different number of reports ( $x$-axis, Published reports), in this cartoon represented as relative size of corresponding light-blue and orange circles, suggest that GDM and OP are differentially associated with increased incidence of human adult diseases ( $y$-axis, Human adult diseases), such as obesity, type 2 diabetes mellitus (T2DM), insulin resistance, hyperlipidaemia, or hypertension. Data taken from $[13,77,78,81$, $84,92,190,195-212]$.

of obesity in children and adolescents [13], a phenomenon leading to high incidence of type 2 diabetes mellitus (T2DM) [14]. OP is also related to neonatal metabolic compromise, which is already apparent in the offspring at birth, characterized by reduced insulin sensitivity and higher concentrations of inflammatory markers [13]. Surprisingly, few studies have been reported regarding the potential association between GDM and OP as pathological conditions of the mother during pregnancy leading to diseases in the adulthood, the latter most likely programmed during the intrauterine life period (Figure 1). These concepts are discussed in this paper in terms of the fetus-placenta interaction and consequences of GDM and OP leading to fetal vascular disturbances. We also suggest that, based in the discussed observations, our attention should be certainly switched towards a better understanding of the gestational period as a key interventional target in the prevention of adult diseases at the state where fetal programming of adult diseases occurs.

\section{Endothelial Dysfunction}

Endothelial cells play a crucial role in the regulation of vascular tone through the release of vasoactive substances, including nitric oxide (NO) $[4,5,15]$. In pathological pregnancies, such as GDM $[6,16]$, intrauterine growth restriction (IUGR) [2], or preeclampsia [17], the synthesis and/or bioavailability of NO are altered leading to changes

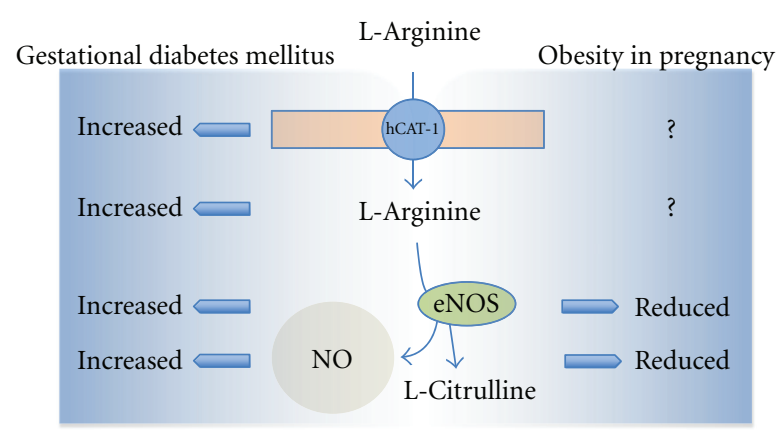

Figure 2: Endothelial L-arginine/NO signalling pathway in gestational diabetes mellitus and obesity in pregnancy. In human endothelial cells L-arginine is taken up via cationic amino acid transporters 1 (hCAT-1) accumulating this amino acid in the intracellular space. L-Arginine is then metabolized by the endothelial nitric oxide synthase (eNOS) into L-citrulline and nitric oxide (NO) as a co-product. Gestational diabetes mellitus is associated with higher expression and activity of hCAT-1 leading to supraphysiological accumulation of L-arginine. This phenomenon results in higher L-arginine metabolism by eNOS due to increased expression and activity of this enzyme leading to overproduction of NO. In endothelial cells from OP there is no information addressing whether this pathological condition alters L-arginine transport and intracellular accumulation, but reduces eNOS expression and activity leading to lower than physiological synthesis of NO.

in blood flow of the human placenta which could result in limiting fetal growth and development $[1,3]$. NO is a gas synthesized from the cationic, semiessential amino acid Larginine in a metabolic reaction leading to equimolar formation of L-citrulline and NO (Figure 2) [5]. This reaction requires the activity of $\mathrm{NO}$ synthases (NOS), of which at least three isoforms have been identified, that is, neuronal NOS (nNOS or type I), inducible NOS (iNOS or type II), and endothelial NOS (eNOS or type III) $[4,5,18]$. The NO diffuses from the endothelium to the underlying layer of vascular smooth muscle cells leading to cyclic GMP (cGMP)dependent vasodilatation [5]. In vessels without innervation, such as the placenta and the distal segment of the umbilical cord $[1,19]$, vascular tone is regulated by the synthesis and release of vasoconstrictors and vasodilators from the endothelium [3]. The reduced ability of this tissue to stimulate NO-mediated vasodilatation is referred to as endothelial dysfunction [20]. This phenomenon is strongly correlated with cardiovascular disease (CVD) risk factors [21] and with early states of chronic diseases such as hypertension [22], hypercholesterolemia [23], diabetes mellitus [24], hyperhomocysteinaemia [25], and chronic renal [26] and cardiac failure [27]. Interestingly, eNOS expression and activity is highly regulated in human fetoplacental microvascular and macrovascular endothelium, an effect that is differential in these two vascular beds; thus, endothelial dysfunction and perhaps increased risk of appearance of chronic diseases in adulthood will also depends on the type of fetal vascular bed that is altered in diseases of pregnancy [16].

Activity of NOS may depend on the ability of endothelial cells to take up their specific substrate L-arginine via a variety 


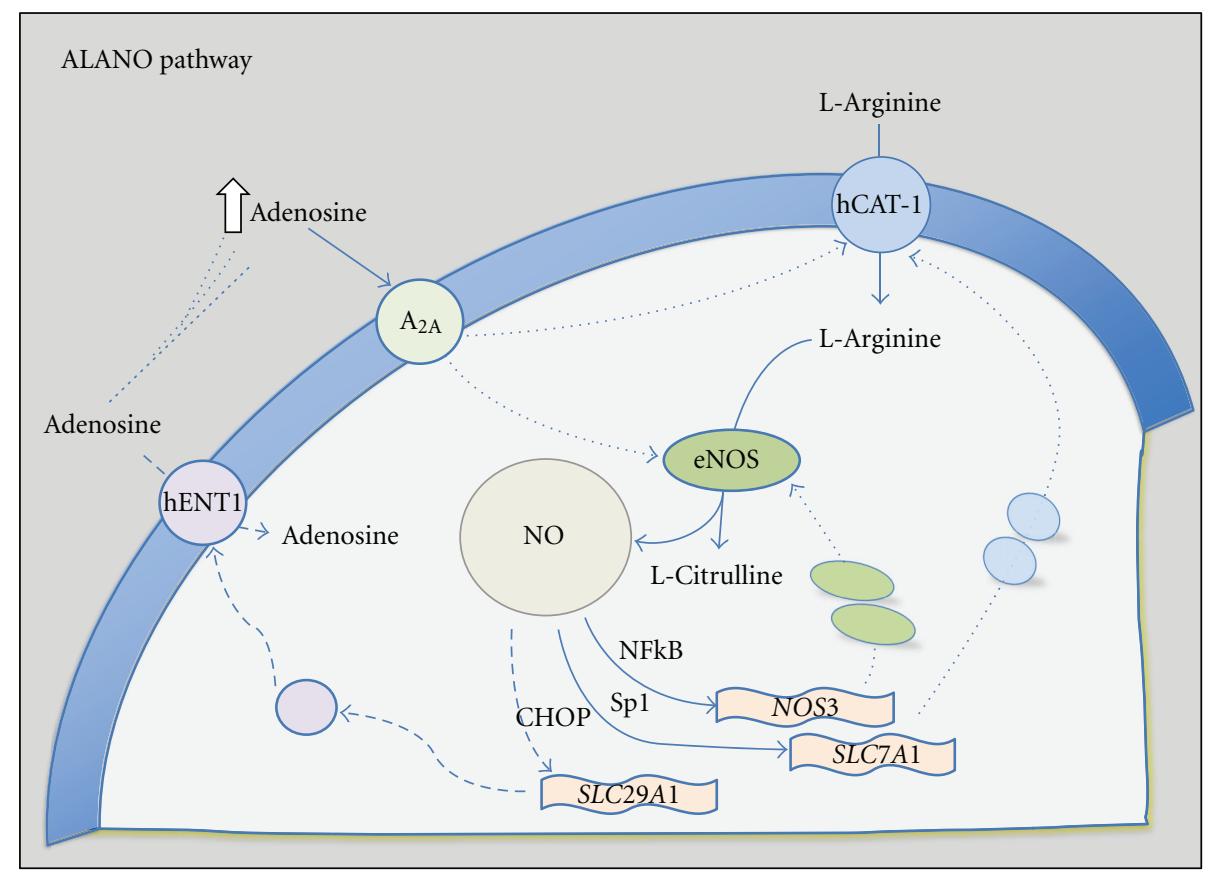

FIgURE 3: Adenosine/L-arginine/nitric oxide (ALANO) signalling pathway in gestational diabetes mellitus. Human umbilical vein (macrovasculature) and placental microvascular endothelial cells exhibit increased (solid light-blue arrows) L-arginine transport via the cationic amino acid transporters 1 (hCAT-1) but reduced (segmented light-blue arrows) adenosine uptake via the equilibrative nucleoside transporter 1 (hENT1). The latter phenomenon leads to accumulation (white up arrow) of adenosine in the extracellular space, which then stimulates $\mathrm{A}_{2 \mathrm{~A}}$ adenosine receptors to activate (dotted light-blue arrows) maximal transport capacity of hCAT-1 and maximal metabolic capacity of endothelial nitric oxide synthase (eNOS) leading to supraphysiological levels of nitric oxide (NO) and L-citrulline. The gas NO activates hC/element-binding protein (CBP) homologous protein 10-C/EBP $\alpha$ transcription factor complex (CHOP) leading to repression of SLC29A1 gene expression resulting in reduced hENT1 protein synthesis and abundance at the plasma membrane. On the other hand, $\mathrm{NO}$ activates the transcription factor-specific protein $1(\mathrm{Sp} 1)$ and nuclear factor $\kappa \mathrm{B}(\mathrm{NF} \kappa \mathrm{B})$ leading to increase transcription of SLC7A1 and NOS3 genes, respectively. This phenomenon results in higher abundance of hCAT-1 and eNOS protein increasing L-arginine transport and NO synthesis. From data in $[6,16,39,48,52,59]$.

of membrane transport systems [2, 28-30]. In human endothelial cells, L-arginine is taken up via membrane transport systems grouped as systems $\mathrm{y}^{+}, \mathrm{y}^{+} \mathrm{L}, \mathrm{b}^{0,+}$, and $\mathrm{B}^{0,+}$ [31-33]. System $\mathrm{y}^{+}$conforms a family of proteins known as cationic amino acid transporters (CATs) (hereafter referred as "CATs family"), with CAT-1, CAT-2A, CAT-2B, CAT-3, and CAT-4 isoforms [34] whose expression and activity, and the mechanisms modulating these phenomena, have been extensively described [30,33-35], including in the human placenta [36-38]. Human fetoplacental endothelium takes up adenosine via equilibrative nucleoside transporters (ENTs) $[6,16,39-41]$. Four members of the ENT family of solute carriers (SLC29A genes) have been cloned from human tissues, that is, hENT1, hENT2, hENT3 and hENT4 $[40,41]$. In primary cultures of human umbilical vein endothelial cells (HUVECs), adenosine transport is mainly $(\sim 80 \%)$ mediated by hENT1 with the remaining transport ( $\sim 20 \%)$ being mediated by hENT2 [39, 42, 43]. Recent reports show that these proteins are also expressed in human placental microvascular endothelial cells (hPMECs); however, contribution of hENT1 and hENT2 to total adenosine transport in this cell type is similar compared with adenosine transport in HUVEC $[17,44]$. hENT3 and hENT4 seem not to play a significant role in endothelium (see $[16,45-47]$ ).
Interestingly, adenosine has been suggested as a nucleoside increasing L-arginine/NO signalling pathway in HUVEC $[39,48]$, hPMEC $[17,49]$, rat cardiomyocytes in response to the ENTs inhibitor dipyridamole [41], and in skeletal microvascular endothelium in response to hypoxia [50]. This phenomenon has been referred to as endothelial "ALANO" signalling pathway (adenosine/L-arginine/nitric oxide) first characterized in HUVEC from GDM pregnancies $[6,16$, 48]. The mechanism involves adenosine activation of $\mathrm{A}_{2 \mathrm{~A}}$ adenosine receptors and increased expression of hCAT- 1 and eNOS, via activation of key signalling molecules including mitogen-activated protein kinases of 42 and $44 \mathrm{kDa}$ $\left(\mathrm{p} 42 / 44^{\mathrm{mapk}}\right)$ and protein kinase C (PKC) $[6,7,16,39$, 48]. Thus, a relationship between expression and activity of hCATs and hENTs in HUVEC from GDM has been established (Figure 3) $[6,16,48,51,52]$.

\section{Gestational Diabetes Mellitus}

Gestational diabetes mellitus (GDM) is a syndrome characterized by glucose intolerance leading to maternal hyperglycaemia first recognized during pregnancy [53]. GDM is associated with abnormal foetal development and perinatal complications, such as macrosomia and neonatal 
hypoglycaemia [54]. Alterations associated with GDM result from a change in the amount of D-glucose available to the fetus due to alterations in the physiology of the placenta (e.g., increased D-glucose transplacental transport) or by hormone-induced dysfunction (e.g., altered insulin signalling), phenomena that could lead to abnormal growth of the fetus (macrosomia) and perinatal complications [16, $55,56]$. Clinical manifestations of GDM have been attributed mainly to the condition of hyperglycaemia, hyperlipidaemia, hyperinsulinemia, and fetoplacental endothelial dysfunction $[54,55]$. Various organs show structural and functional alterations, including endothelial dysfunction of the microand macrocirculation in the fetoplacental circulation, in GDM $[16,57]$. Increased NO synthesis has also been reported in human placental veins and arteries [58] and in primary cultures of HUVEC $[7,51,59]$ isolated from pregnancies with GDM (Table 1). Thus, vascular dysfunction resulting from this syndrome may be a consequence of a functional dissociation between the synthesis of $\mathrm{NO}$ and/or its bioavailability to the vascular endothelium and smooth muscle in the human placenta circulation. Even when the GDM-associated endothelial dysfunction regards altered endothelial L-arginine/NO signalling pathway, most studies regarding the mechanisms behind these effects of GDM are not conclusive. However, it is conceivable that these alterations are the result of alterations in multiple, rather than single, metabolic mechanisms including sensitivity of the human fetal endothelium to vasoactive molecules such as adenosine $[39,48]$ or insulin $[7,47]$.

\subsection{Endothelial Dysfunction in Gestational Diabetes Mellitus}

3.1.1. L-Arginine/NO Signalling Pathway. In primary cultures of HUVEC from GDM, synthesis of NO [7, 39, 59], L-arginine transport [39], and its intracellular concentration [16] are increased (Figure 2). GDM-associated increase of Larginine transport is due to higher maximal velocity $\left(V_{\max }\right)$ for transport, most likely resulting from higher hCAT-1 expression [39]. Since general activators of PKC increase Larginine transport and because activation of $\mathrm{p} 42 / 44^{\mathrm{mapk}}$ is increased in response to $\mathrm{NO}$ and $\mathrm{PKC}$, the mechanisms by which L-arginine transport is activated in GDM in HUVEC seem to depend on these intracellular signalling molecules.

PKC and $\mathrm{p} 42 / 44^{\mathrm{mapk}}$ are also involved in the stimulation of L-arginine transport via hCAT-1 by insulin in HUVEC $[30,33,47,60]$. This phenomenon seems to result from increased SLC7A1 (for hCAT-1) promoter transcriptional activity via a mechanism involving the zinc finger promoter-selective transcription-factor-specific protein 1 (Sp1) binding to multiple consensus sequences identified between -177 and $-105 \mathrm{bp}$ from the ATG (transcription starting sequence) of this gene [33]. Insulin causes relaxation of human umbilical vein rings in an endothelium- and hCAT-like transport activity-dependent manner [33]. Since this vascular response is found using physiological plasma concentrations of insulin $(\sim 0.01-0.1 \mathrm{nM})$, it is feasible that SLC7A1 expression and most likely hCAT-1 activity are under tonic regulation by physiological insulinemia in human umbilical veins. Insulin-induced umbilical vein relaxation was lower in vessels from GDM compared with normal pregnancies [7]. This phenomenon could be the result of a less reactive umbilical vein, perhaps due to tonic and basally increased vasodilation due to overrelease and/or accumulation of adenosine at the umbilical vein blood [7]. In addition, it is known that insulin effect in patients with insulin resistance is improved by infusion of adenosine receptor agonists suggesting that insulin biological effects could be facilitated upon adenosine receptor activation [61]. This mechanism is also plausible in the human fetoplacental circulation where activation of adenosine receptors is also, apparently, facilitating insulin-increased L-arginine/NO signalling pathway [47]. Altogether these findings could be crucial for fetal insulin modulation of endothelial-derived NO synthesis in human umbilical vessels from pregnancy diseases associated with hyperinsulinemia, such as GDM, and other states of insulin resistance $[6,7,16,30,47]$.

\subsubsection{Adenosine Transport. HUVEC from GDM also exhibit} reduced adenosine transport (Figure 3) [6, 16]. GDM effect on adenosine uptake is proposed to result from a lower hENT1 transport capacity $\left(V_{\max } / K_{\mathrm{m}}\right)$ due to reduced $V_{\max }$ rather than altered intrinsic properties (i.e., unaltered apparent $K_{\mathrm{m}}$ ) of this type of nucleoside transporters [7, 51, 59]. Since adenosine uptake efficiency (i.e., adenosine molecules per transporter per cell per second) is unaltered in HUVEC from GDM [62], reduced hENT1 expression could explain this effect of GDM. Alternatively, a lower number of nucleoside-binding sites per endothelial cell $(\sim 50 \%)$ have been estimated in HUVEC from GDM compared with cells from normal pregnancies [62]. In addition, an apparent recycling of hENT1 from the plasma membrane to perinuclear location has been shown in this cell type $[63,64]$. Thus, not only a reduced activity and expression but also hENT1 recycling could be a mechanism involved in GDM altered adenosine transport in human fetal endothelium $[16,65,66]$. It is also known that NO inhibits SLC29A1 (for hENT1) promoter transcriptional activity in HUVEC from GDM, where a higher NO synthesis due to eNOS activation (phosphorylation of eNOS at $\operatorname{Ser}^{1177}$ residue) [39] as well as increased total eNOS expression [59] is reported. The SLC29A1 promoter region spanning from -2154 to $-1810 \mathrm{bp}$ from the ATG contains sequence(s) for inhibitory transcription factor(s) leading to downregulation of this gene expression in HUVEC from GDM [59]. Interestingly, GDM effect requires activation of the NO-dependent repressive transcription factors complex conformed by $\mathrm{hC} /$ element-binding protein homologous protein 10 (CHOP)-CCAAT/enhancer-binding protein $\alpha(\mathrm{C} / \mathrm{EBP} \alpha)$ $($ hCHOP-C/EBP $\alpha$ ) [51]. These regulatory mechanisms of hENT1 expression and/or intracellular localization could be key events to understand the recently reported GDMincreased plasma adenosine concentration $(\sim 600 \mathrm{nM})$ in umbilical vein blood [7] compared with normal pregnancies $(\sim 350 \mathrm{nM})$ [7, 67-69]. Reduced expression and/or activity of hENTs is a phenomenon that could also explain the elevated extracellular adenosine concentration detected in the culture medium of HUVEC from GDM $(\sim 900-2,000 \mathrm{nM})$ [7] compared with normal $(\sim 50-500 \mathrm{nM})$ pregnancies $[7,69]$. 
TABLE 1: Effect of GDM, obesity, and hypercholesterolaemia on ALANO signalling pathway.

\begin{tabular}{|c|c|c|c|c|c|c|c|c|c|}
\hline \multirow{3}{*}{ Element } & \multirow{2}{*}{\multicolumn{3}{|c|}{$\begin{array}{c}\text { Pregnancy } \\
\text { GDM }\end{array}$}} & \multicolumn{6}{|c|}{ Nonpregnancy } \\
\hline & & & & \multicolumn{3}{|c|}{ Obesity } & \multicolumn{3}{|c|}{ Hypercholesterolemia } \\
\hline & Cell type & Effect & References & Cell type & Effect & References & Cell type & Effect & References \\
\hline \multirow{2}{*}{ hENT1 expression } & HUVEC & Reduced & {$[7,39,51]$} & & & & & & \\
\hline & hPMEC & Reduced & {$[16,44]$} & & & & & & \\
\hline \multirow{2}{*}{ hENT1 activity } & HUVEC & Reduced & {$[7,39,51]$} & & & & & & \\
\hline & hPMEC & Reduced & {$[16,44]$} & & & & & & \\
\hline \multirow{2}{*}{ hENT2 expression } & HUVEC & Unaltered & [16] & & & & & & \\
\hline & hPMEC & Reduced & {$[16,44]$} & & & & & & \\
\hline \multirow{2}{*}{ hENT2 activity } & HUVEC & Unaltered & {$[16]$} & & & & & & \\
\hline & hPMEC & Reduced & {$[16,44]$} & & & & & & \\
\hline Extracellular adenosine & HUVEC & Increased & {$[7,48]$} & & & & & & \\
\hline \multirow[t]{2}{*}{ hCATs, expression } & HUVEC & Increased & {$[39]$} & $\mathrm{hP}$ & Reduced & {$[213]$} & EAhy926 & Increased & {$[128]$} \\
\hline & & & & & & & rAR & Increased & {$[127]$} \\
\hline \multirow[t]{6}{*}{ hCATs, activity } & HUVEC & Increased & {$[39]$} & $\mathrm{hP}$ & Reduced & {$[213]$} & EAhy926 & Increased & {$[128]$} \\
\hline & & & & & & & rAR & Reduced & {$[127]$} \\
\hline & & & & & & & bAEC & Reduced & {$[214]$} \\
\hline & & & & & & & pAEC & Reduced & {$[215]$} \\
\hline & & & & & & & HUVEC & Unaltered & {$[216]$} \\
\hline & & & & & & & HUVEC & Unaltered & {$[217]$} \\
\hline \multirow{4}{*}{ eNOS expression } & HUVEC & Increased & {$[39,51]$} & hVEC & Unaltered & {$[173]$} & hSVEC & Reduced & [129] \\
\hline & hPT & Increased & [218] & mVEC & Increased & [219] & rbAS & Reduced & {$[131]$} \\
\hline & & & & hAd & Increased & {$[220]$} & HUVEC & Reduced & {$[130]$} \\
\hline & & & & hHep & Unaltered & {$[221]$} & & & \\
\hline \multirow{4}{*}{ eNOS activity } & HUVEC & Increased & {$[7,39,51]$} & hVEC & Reduced & {$[173]$} & hSVEC & Reduced & {$[129]$} \\
\hline & hVT & Unaltered & [222] & mVEC & Reduced & [219] & rbAR & Reduced & {$[131]$} \\
\hline & & & & mHep & Reduced & {$[223]$} & HUVEC & Reduced & {$[130]$} \\
\hline & & & & $\mathrm{hP}$ & Unaltered & {$[213]$} & pAEC & Reduced & {$[215]$} \\
\hline NO level & HUVEC & Increased & {$[11]$} & * & Increased & {$[221]$} & hSVEC & Reduced & {$[129]$} \\
\hline Arginase 1 & & & & mHep & Increased & {$[223]$} & & & \\
\hline \multirow[t]{2}{*}{ Arginase 2} & & & & & & & hAEC & Increased & [136-138] \\
\hline & & & & & & & mAEC & Increased & {$[137,138]$} \\
\hline
\end{tabular}

hENT1: human equilibrative nucleoside transporter 1; hENT2: human equilibrative nucleoside transporter 2; hCATs: human cationic amino acid transporters; eNOS: endothelial nitric oxide synthase; NO: nitric oxide; HUVEC: human umbilical vein endothelial cell; hPMEC: human placental microvascular endothelial cell; hPT: human placental tissue; hVT: human villous tissue; hP: human platelets; hVEC: human vascular endothelial cell; mVEC: mouse vascular endothelial cell; hAd: human adipocyte; hHep: human hepatocyte; mHep: mouse hepatocyte; EAhy 926: human endothelial cell line EAhy 926; rAR: rat aortic ring; bAEC: bovine aortic endothelial cell; pAEC: porcine aortic endothelial cell; hSVEC: human saphenous vein endothelial cell; rbAS: rabbit aortic segment; rbAR: rabbit aortic ring; hAEC: human aortic endothelial cell; mAEC: mouse aortic endothelial cell; * measurement performed in human serum.

Insulin also reduces hENT1-mediated adenosine transport in HUVEC from normal pregnancies but restores GDM-associated reduced hENT1 expression and activity in this cell type $[7,70]$. One of the proposed mechanisms accounting for this beneficial effect of insulin on adenosine transport is an activation of $\mathrm{A}_{2 \mathrm{~A}}$-adenosine receptors by extracellular adenosine, which is increased due to reduced hENT1 transport activity in this cell type. In addition, a role for a differential expression of insulin receptor isoforms A (IR-A) and B (IR-B) in HUVEC from GDM is proposed [7]. In this phenomenon insulin would be acting as a factor that restores a potential GDM-associated metabolic phenotype (i.e., preferential activation of $\mathrm{p} 42 / 44^{\mathrm{mapk}}$ over Akt pathways) to a normal, mitogenic phenotype (i.e., preferential activation of Akt over p42/44 ${ }^{\text {mapk }}$ pathways) by restoring IR-A expression to values in HUVEC from normal pregnancies [7]. Similar findings have been recently reported for endothelial cells from the microcirculation of the human placenta from GDM pregnancies, where instead a differential role for insulin receptor isoforms is played as modulator of hENT2-mediated adenosine transport [39].

In a recent study it has been proposed that diabetes mellitus is not triggered in experimental animals where arginases activity is increased, a phenomenon proposed to be due to reduced NO synthesis [71]. These findings highlight the importance of the counterregulatory effect of arginases and NOS in pathologies where vascular tone regulation is altered [72]. It is likely that increased arginase activity leads to lower L-arginine bioavailability for eNOS impairing NO synthesis in the endothelium (see Figure 4). Interestingly, 


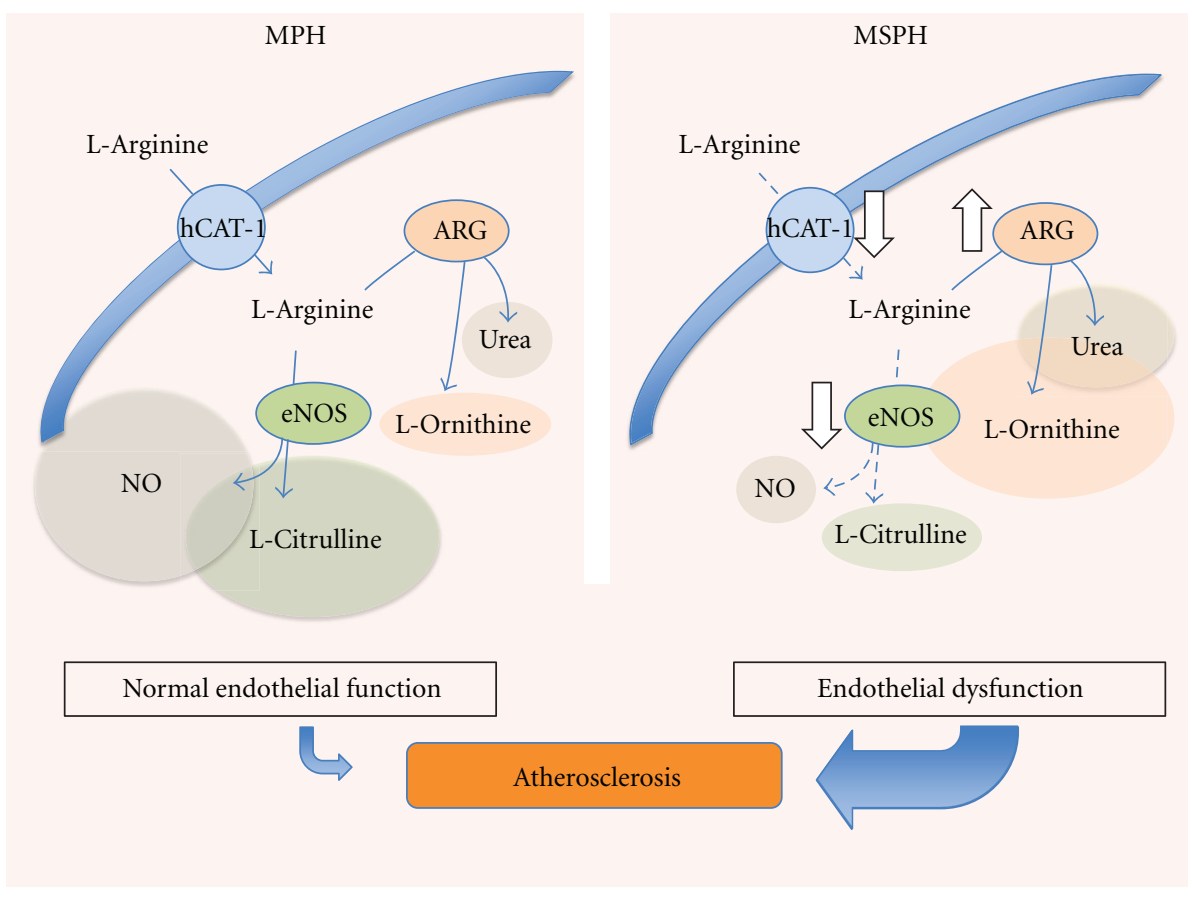

FIgURE 4: L-Arginine metabolism in hypercholesterolaemia. In human endothelial cells, L-arginine is taken up via cationic amino acid transporter 1 (hCAT-1) which is then metabolized by either the endothelial nitric oxide synthase (eNOS) into L-citrulline and nitric oxide (NO), or via arginases (ARG) into L-ornithine and urea, phenomena conforming a normal endothelial function phenotype. These mechanisms occur in a condition recognized as maternal physiological hypercholesterolaemia (MPH), which has been shown to be associated with early states of fetal vasculature atherosclerosis. However, in a state of maternal supraphysiological hypercholesterolaemia (MSPH) (see text), hCAT-1 and eNOS expression and activity are reduced (white down arrow) leading to reduced (segmented light-blue arrows) Larginine uptake and NO synthesis, respectively. However, a higher (white up arrow) expression and activity of ARG (most likely arginase 2) leads to increased formation of L-ornithine and urea. The alterations seen in endothelial cells from pregnancies with MSPH result in endothelial dysfunction contributing in a larger proportion to fetal vasculature atherosclerosis compared with MPH. From data in $[129,130,136,138]$.

exogenous L-citrulline, but not L-arginine, and inhibition of arginases induce a diabetic phenotype in rats [71]. Therefore, it is also feasible that recycling of L-citrulline to L-arginine could also be involved in this phenomenon. The fact that L-arginine does not induce diabetes could mean that Larginine availability for NOS is compartmentalized at such degree that it could not reach appropriate concentrations to activate NOS ( $K_{\mathrm{m}}$ of eNOS for L-arginine ranges $\left.1-10 \mu \mathrm{M}\right)$ [5], thus limiting the use of this amino acid in the treatment of GDM. What will be the impact of these mechanisms in the fetoplacental circulation, and whether these mechanisms will be associated with programming of adulthood diseases, is unknown.

3.2. Dyslipidaemia. GDM is a pathological condition also characterized by maternal dyslipidaemia, alteration directly affecting fetal development and growth [56]. Dyslipidaemia is defined as elevated levels of triglycerides (hypertriglyceridemia) and total blood cholesterol (hypercholesterolemia), including increased low-density lipoprotein (LDL) and reduced high-density lipoprotein (HDL) levels [73]. This phenomenon is associated with the development of endothelial dysfunction and atherosclerosis (a progressive disease characterized by formation of lipid plaques in arteries) [73, 74]. Dyslipidaemia is the main risk factor for development of CVD [73, 75, 76]. Additionally, GDM is a risk factor to fetal programming due apparently to metabolic syndrome [77-79] and, thus, predisposes to an accelerated development of CVD in adult life [78-83]. Interestingly, most of pregnancies with GDM course with dyslipidaemia, thus making feasible a pathological link (i.e., most likely potentiation) between dyslipidaemia in GDM pregnancies and development of CVD later in life. In fact, GDM could play a role in fetal programming of adult CVD not only by alterations in endothelial function of the placenta (mainly triggered by hyperinsulinemia, hyperglycaemia, and changes in nucleoside extracellular concentration) but also by dyslipidaemia associated with this pathology $[79,84]$.

3.2.1. Hypertriglyceridemia. Pregnancy is a physiological condition characterized by a progressive weeks of gestationdependent increase (reaching 100-200\%) in the maternal blood level of triglycerides $[85,86]$. These changes promote accumulation of maternal fat stores in early and mid pregnancy, so to metabolize and use it in late pregnancy. The very-low-density lipoprotein (VLDL) is the type of 
triglycerides carrier that increases in major proportion in the plasma in hypertriglyceridemia. This phenomenon results from an enhanced VLDL production by the liver and decreased removal of this lipoprotein from the circulation as a consequence of pregnancy-associated hormonal changes, including insulin-resistant condition and elevated plasma oestrogen $[85,87]$. The characteristic fetal macrosomia in GDM is also a phenomenon related with alterations in lipid metabolism leading to increased supply of nutrients to the fetus favouring its growth [88]. The association between dyslipidaemia and macrosomia regards hypertriglyceridemia more than hypercholesterolemia; in fact, a positive correlation between maternal triglycerides and neonatal body weight or fat mass has been found in GDM [86, 88, 89]. Furthermore, since triglycerides cross the placenta [1] and contribute to fetal macrosomia [87], maternal plasma concentration of these lipids in the third trimester of gestation, which could result from higher concentration of fatty acids derived from maternal triacylglycerol, is considered as a strong predictor of birth weight in women with GDM [90-92]. This phenomenon is related with altered placenta expression of key proteins involved in de novo lipid synthesis (fatty acid synthase and sterol regulatory elementbinding protein 2) [93], triglycerides metabolism (placental fatty acid-binding protein) [94, 95], and genes related with placental lipid pathways accounting for placental lipid metabolism and transport (e.g., PLA2G5 for phospholipase $\mathrm{A}_{2}, L P L$ for lipoprotein lipase, $F A C L 3$ for fatty acid-coenzyme A ligase) [96]. It is accepted that regulation of these genes in GDM alters placenta and fetus lipid metabolism leading to altered fetal development and size, a condition potentiating fetal hyperinsulinemia's biological effects and contributing to the development of the metabolic syndrome and CVD later in life $[79,96]$.

3.2.2. Hypercholesterolemia. Pregnancy is also characterized by a progressive and weeks of gestation-dependent increase $(40 \%-50 \%)$ in the maternal blood level of cholesterol [85, 97, 98]. This phenomenon is known as maternal physiological hypercholesterolemia in pregnancy (MPH) and is considered to be an adaptive response of the mother to satisfy the high lipids demand by the growing fetus $[85,86]$. However, when a maternal misadaptation to the cholesterol demands by the fetus occurs, a group of these women develop a pathological condition referred to as maternal supraphysiological hypercholesterolemia (MSPH). This condition is characterized by maternal blood cholesterol level to be over the 95th percentile or following the establishment of a cut-point $>280 \mathrm{mg} / \mathrm{dL}[93,99-101]$. Sources of cholesterol for fetal metabolism along with endogenous production by fetal tissues include transplacental mother-to-fetus transport of maternal cholesterol [93, 100-106]. Although lipid traffic through the placenta is restrictive, a correlation between maternal and fetal blood cholesterol in the first and second trimesters of pregnancy has been established [100, 107]. These studies suggest that maternal cholesterol level alters normal development of the fetus. In fact, it has been reported that, due to altered lipid metabolism in the placenta as a result of high maternal blood cholesterol, atherogenesis, a clinical complication commonly appearing in adults, probably begins in fetal life with likely similar factors altered in the mother, the fetus, and the placenta (see Figure 5) $[100,108-111]$. This phenomenon was for the first time referred to as the "foetal hypothesis of atherosclerosis" [100, 112]. Interestingly, a strong correlation between maternal cholesterolaemia before and during pregnancy and the size of atherosclerotic lesions in arteries of fetus, children, and young adults has been shown $[100,101,111,112]$. This is apparently crucial regarding fetal programming of CVD [109-113]. Potential clinical implications for this foetal hypothesis of atherosclerosis were further contextualised with the FELIC ("Fate or Early Lesions in Children") study [101] where the possibility of applying a therapy to mothers with hypercholesterolaemia during pregnancy complemented with described pathogenic insights in the primary prevention of CVD, including stem cell therapy [114], is suggested as a potential way to improve health in their children [101]. Alternatively, C-reactive protein blood levels were described as higher in mothers with hypercholesterolaemia during pregnancy, and this finding was proposed to be used as a predictor of increased atherogenesis in children [115]; however, even when this information is of relevance for preventive medicine, maternal cholesterolaemia seems to be a stronger predictor.

Placental vascular dysfunction, including altered macroand microvascular endothelial altered function, is associated with higher risk of developing CVD in adulthood [16, 57]. Cumulative evidence shows that high levels of blood cholesterol modify the endothelial function in different vascular beds [116], mostly associated with reduced vascular NO bioavailability and elevated oxidative stress (Table 1). Unfortunately, nothing is reported regarding whether abnormal maternal blood cholesterol level, including MSPH, leads to placental vascular endothelial dysfunction [109, 117]. GDM correlates with placental macro- and microvascular endothelial dysfunction [16], also considered as early marker of atherosclerosis [77]. Neonates with macrosomia from GDM pregnancies show a significant increase in the aortic intimamedia thickness and higher lipid content, both conditions considered as subclinical markers of atherosclerosis [110, 118] and that will potentially increase the atherosclerotic process later in life. Nothing is yet available regarding the potential effect of MSPH in normal or GDM pregnancies regarding development of atherosclerosis in the fetoplacental vasculature in humans $[16,118]$. Preliminary findings from our group suggest that MSPH is associated with reduced (in fact almost abolished) vasodilatation of human umbilical vein rings in response to insulin (Figure 6), a phenomenon that could be mediated by endothelial dysfunction since NO synthesis is also altered in HUVEC from these patients [119]. Thus, we speculate that MSPH becomes a pathological condition triggering potentiation of GDM effect on fetal programming of CVD.

Reduced vascular NO bioavailability and elevated oxidative stress alter vascular reactivity in the placenta [120], as well as in children $[121,122]$ and adults $[120,123-$ 125], phenomena including downregulation of L-arginine transport and eNOS activity in endothelial cells. Several 


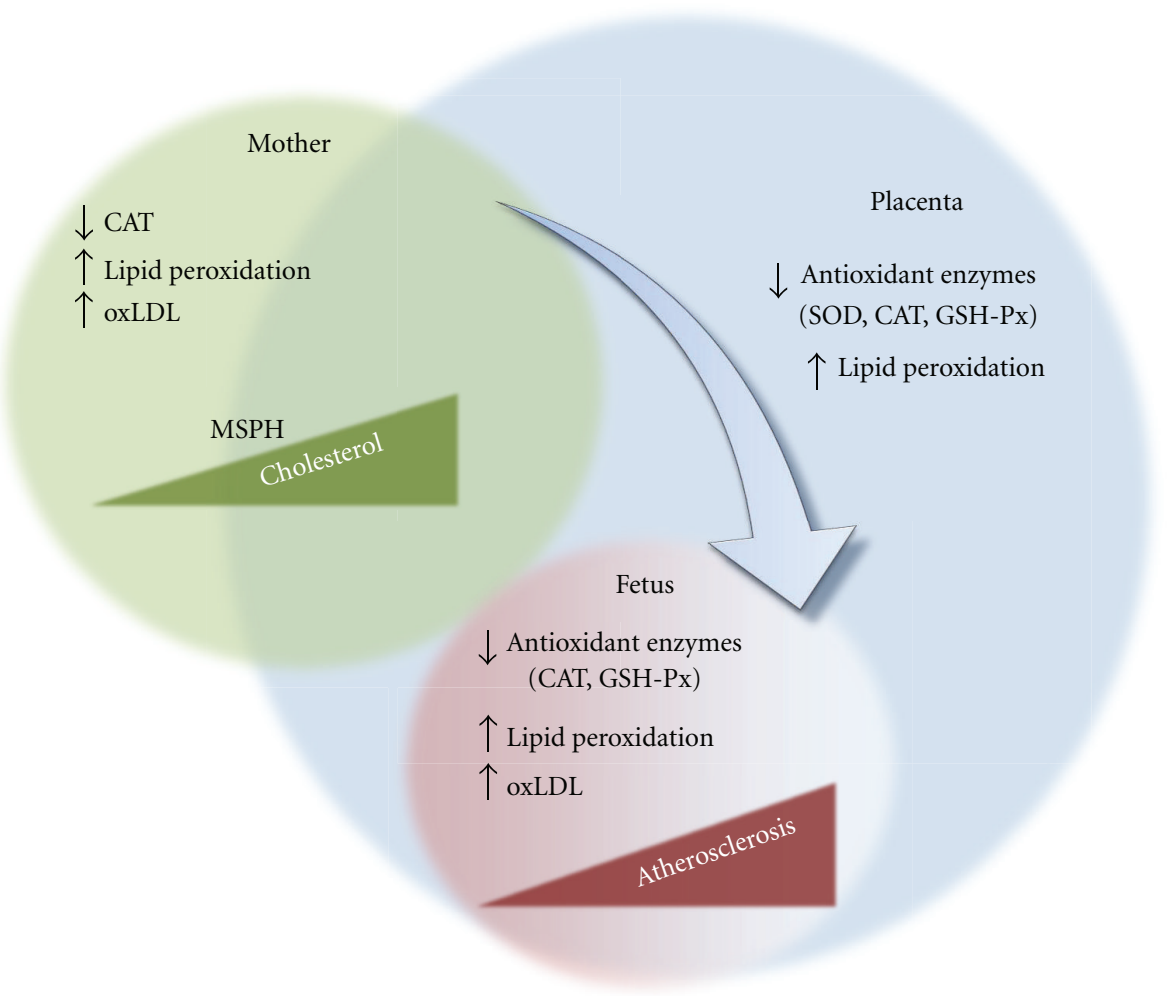

Figure 5: Potential pathophysiological interaction between the mother, the placenta, and the fetus in fetal atherosclerosis. Maternal factors, including reduced $(\downarrow)$ catalase (CAT) activity, increased $(\uparrow)$ lipid peroxidation, and oxidized low density lipoproteins (oxLDL), associated with increased cholesterol content at the mother circulation, generate a state of maternal supraphysiological hypercholesterolaemia (MSPH). This phenomenon leads to similar alterations in the placenta (reduced CAT, superoxide dismutase (SOD), glutathione-peroxidase (GSH-Px) activity) and the fetus (with reduced CAT and GSH-Px and increased lipid peroxidation and oxLDL). Therefore, atherosclerosis in the fetus is identified. Data taken from $[88,100,101,109,110]$.

alterations caused by hypercholesterolemia could explain these changes in vascular reactivity [126]. To date, (a) cholesterol-enriched diet [127] or oxidized low-density lipoproteins (oxLDLs) [128] cause a posttranscriptional downregulation of hCATsmediated L-arginine transport in rat aortic rings and in the human endothelial cell line EAhy926, (b) hypercholesterolemia leads to reduced NOS expression in human saphenous vein endothelial cell, rabbit aortic segments, and HUVEC [129-131], the latter likely due to increased expression of eNOS mRNA destabilizing cytosolic proteins [130,131], and (c) eNOS cofactor tetrahydrobiopterin $\left(\mathrm{BH}_{4}\right)$ expression is reduced in mice and rabbit aortic rings $[132,133]$ most likely due to downregulation of guanosine triphosphate cyclohydrolase I (GTPCH, a key enzyme involved in the $\mathrm{BH}_{4}$ synthesis) $[134,135]$. In addition, hypercholesterolemia is also associated with increased expression and activity of arginases resulting in reduced NO synthesis in human and mice aortic endothelial cells [136-138]. Preliminary results show that in fact arginase II protein abundance is increased in HUVEC from patients with MSPH compared with normal pregnancies (A. Leiva, P. Casanello, and L. Sobrevia, unpublished results). Therefore, we speculate that similar mechanisms may be either triggered or potentiated by MSPH with direct consequences in the fetoplacental endothelial L-arginine/NO pathway (Figure 4), a phenomenon not at all evaluated in pregnancies coursing with GDM $[16,86]$.

\section{Obesity in Pregnancy}

Obesity is a syndrome estimated to be pandemic with a large fraction of children now diagnosed as obese, where causes, other than malnutrition after birth, are not fully explanatory [139]. Obesity is a pathology resulting from a misbalance between the energy intake and energy used, with an overstorage of lipids in adipose tissue [140]. This pathology also courses with systemic metabolic misbalance leading to occurrence of multiple complications, such us dyslipidaemia and insulin resistance [141], and endothelial dysfunction leading to hypertensive disorders (Figure 1) [142, 143]. Incidence of obesity in the world is currently increasing reaching up to $\sim 12 \%$ of the population [143]. Worryingly, increased obesity incidence includes $\sim 29 \%$ of women in their reproductive age [144]. Much evidence now available involves differential contribution of genetic and environmental factors in the development of obesity, diabetes mellitus, or CVD. Thus, prevention of childhood and adult obesity may require beginning even before conception [145-147]. 


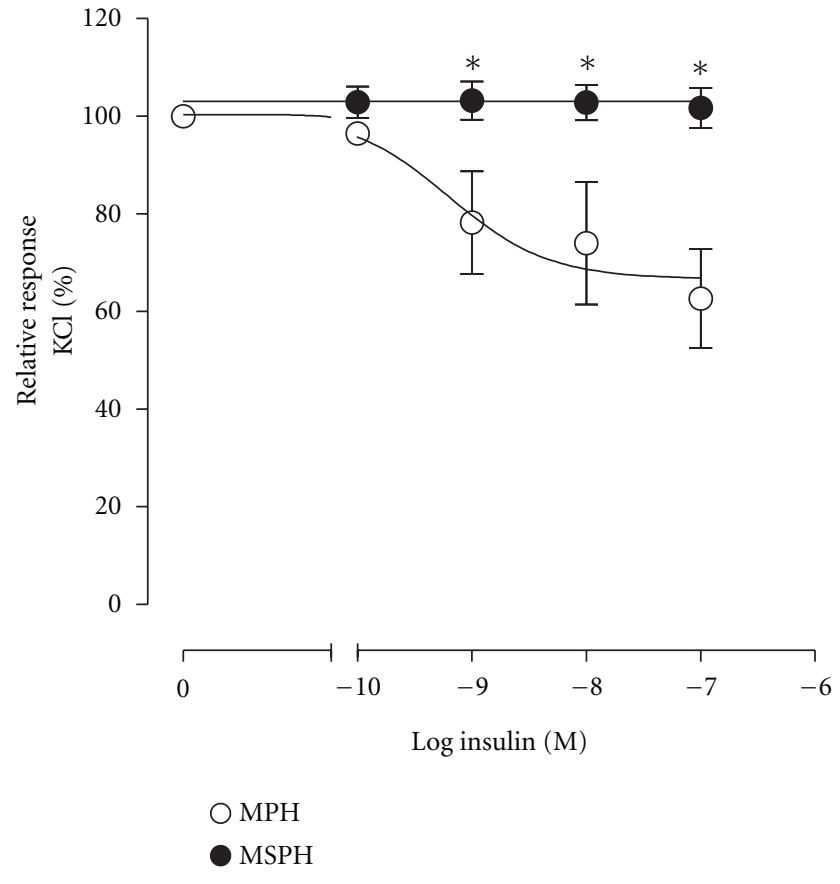

Figure 6: Insulin effect on human umbilical vein ring reactivity. Endothelium-intact human umbilical vein rings were isolated from umbilical veins taken from pregnancies with maternal physiological hypercholesterolaemia (MPH) or maternal supraphysiological hypercholesterolaemia (MSPH). Umbilical vessel ring segments (2-4 mm length) were mounted in a myograph for isometric force measurements with optimal diameter adjusted from maximal active response to $62.5 \mathrm{mM} \mathrm{KCl}$ as previously described [28, 107]. Acute response to insulin ( 3 minutes) was determined in $\mathrm{KCl}-$ preconstricted vessels in preparations incubated in Krebs. Values are mean $\pm \operatorname{SEM}(n=7) .{ }^{*} P<0.05$ versus corresponding values in $\mathrm{MPH}$.

Obesity in pregnancy is associated with fetal mortality and morbidity, congenital malformations, macrosomia, and increased incidence of caesarean delivery [148-151], thus making this syndrome a condition that once declared in pregnancy alters foetal growth and development. Even when an inflammatory profile in placental tissue from obese women has been described [152-154], the consequences of OP on fetoplacental vasculature function, including expression and function of the endothelial L-arginine/NO signalling pathway, remain mostly unknown (Figure 2, Table 1) [16]. Even when GDM $[6,16,56,155]$ and obesity $[142,156$, 157] are syndromes associated with altered human vascular function, there are no studies addressing a potential link between placental dysfunction in GDM and OP. However, it is known that OP is associated with higher risk of developing GDM [158], a possibility supported by findings showing that OP correlates with overgrown fetuses [149], intrauterine growth restriction [154], and preeclampsia [159-161]. These results are demonstrative that $\mathrm{OP}$ is a key risk factor for pregnancy and fetal development, a condition that could lead to programming of diseases of the adulthood (Figure 1).
4.1. Endothelial Dysfunction in Obesity in Pregnancy. Several studies associate obesity with chronic inflammation since blood markers, such as the proinflammatory cytokine interleukin 6 (IL-6) and tumour necrosis factor $\alpha$ (TNF $\alpha$ ), are increased in these patients [162-166]. The endothelium is the first cell line exposed to these cytokines [167170] leading to altered eNOS expression and activity and reduced NO bioavailability [171-174]. Moreover, placentas from patients with $\mathrm{OP}$ exhibit a higher inflammatory profile with increased expression of interleukin 1 (IL-1), IL-8, and chemoattractant protein 1, compared with lean women [153]. These findings are complemented by reports showing obesity-associated increase of IL- 6 and TNF $\alpha$ level, with higher heterogeneous macrophage infiltration in the human placenta [152]. In addition, in a sheep model of OP describing this inflammatory profile, JNK and NF $\kappa \mathrm{B}$ signalling pathway involvement in the placental tissue has been reported [175]. Thus, OP could become a condition altering placental endothelial function with consequences to the fetus at birth and potentially in the adulthood.

Leptin, a hormone whose circulating level is increased in obesity [176], increases system A transport activity through activation of STAT3 and activation of JAK-STAT signalling pathway in human placental villous [177]. However, hyperleptinaemia in obese pregnant women was also shown to correlate with reduced activity of system A, an effect most likely due to increased leptin resistance by the placental tissue [178]. Regarding nucleoside transport, there are no studies addressing this phenomenon, including hENT activity and/or expression, in obese subjects, including pregnant women [142]. Interestingly, NO level is higher in obese subjects [179] and rats [180], and the transcription factor complex hCHOP-C/EBP $\alpha$, known to cause NO-dependent downregulation of SLC29A1 expression in HUVEC from GDM pregnancies (see above) [51], is also expressed in human adipocytes and involved in the downregulation of expression of other membrane transporters, such as SCL2A4 (for GLUT4) [181]. In addition, obesity is also associated with altered insulin signalling in several tissues and activates MAPK signalling cascades enhancing insulin resistance [182]. Even when the above-described mechanisms are involved in downregulation of hENT1 expression in the human placental vascular endothelium from GDM, nothing is reported regarding OP effect in this phenomenon.

\subsection{Postnatal Outcome in Offspring in Obesity in Pregnancy.} Prepregnancy obesity and excessive gestational weight gain have been implicated in an intergenerational "vicious cycle" of obesity, since overweight or obese women give birth to macrosomic girls, who are more likely to become obese themselves and deliver large-sized neonates [183]. In fact, gestational weight gain and birth weight were directly associated with the body mass index and the risk of obesity in adolescence $[184,185]$. The relationship described was independent of parental characteristics, potentially mediating peripartum factors, child obesogenic behaviour, and weight at birth, suggesting a role of the intrauterine environment on long-term offspring weight regulation. Interestingly, an association between weight gain of the mother during 
pregnancy and increased risk of greater adiposity in the offspring has been shown at ages of infancy as early as 7 [186] or 3 years old [187]. Considering the high prevalence of OP and its potential association with GDM [158], there is an increasing interest in considering a potentially negative influence of maternal overnutrition and raised birth weight on the risk of disease in childhood and adulthood [148, $183,188]$. Children of obese women exhibiting increased risk of diabetes in pregnancy are more likely to develop insulin resistance later in life [189] (Figure 1). An association between maternal weight gain during pregnancy and prepregnancy weight with offspring cardiovascular risk factors in 9 years old children has been proposed (Avon Longitudinal Study of Parents and Children, ALSPAC) [190]. This study shows that women gaining more than recommended weight during gestation were more prone to have offspring with greater body mass index, waist, fat mass, leptin, systolic blood pressure, C-reactive protein, and interleukin-6 levels but lower HDL cholesterol and apolipoprotein A levels than women with a physiological weight gain. Additionally, greater prepregnancy weight was independently associated with greater offspring adiposity and adverse cardiovascular risk factors, agreeing with previous studies [191-195]. Epidemiological studies show that OP increases the incidence of metabolic syndrome in children [188]. Interestingly, OP is related to neonatal metabolic compromise already apparent at birth, characterized by reduced insulin sensitivity and increased serum inflammatory markers [13]. Since OP effect on the susceptibility to obesity in offspring is apparently independent of GDM, as obese women with normal blood glucose have babies with increased adiposity [196], OP and excessive maternal weight gain during pregnancy are independent factors leading to increased risk of obesity, insulin resistance, and early markers of CVD in the offspring. All this evidence shifts our attention towards the gestational period as an extremely key interventional target in the prevention of obesity and associated consequences such as insulin resistance and cardiovascular risk.

4.2.1. Mechanisms of Adverse Postnatal Outcome. The molecular mediators and signalling pathways from the mother to program the metabolic phenotype (i.e., obesity and insulin resistance) of the developing offspring are not fully elucidated. Hormones, such as leptin and insulin, or nutrients, such as D-glucose, free fatty acids, and triglycerides, and multiple inflammatory cytokines could be implicated. During normal intrauterine life, maternal insulin does not cross the placenta, whereas maternal D-glucose is actively transferred to the fetus [197]. The developing fetal pancreas responds to a D-glucose load by increasing synthesis and release of insulin, which acts as a fetal growth hormone. This is the basic concept of the "Pedersen's hyperglycaemiahyperinsulinism hypothesis" (where fetal overgrowth due to hyperinsulinemia in response to increased transplacental D-glucose transfer is proposed, as recently reviewed [224]) explaining observations showing that offspring of diabetic mothers exhibit high birth weight [225]. Further analysis expanded this theory to include the possibility that other insulin secretagogues, including free fatty acids, ketone bodies, and amino acids [197]. Maternal overnutrition produces hyperglycaemia, which leads to increased fetal insulin secretion in a similar manner as seen in GDM [226]. Thus, secondary fetal hyperinsulinemia is believed to be involved in the intrauterine programming of obesity and diabetes [188]. Prospective studies indicate that at birth and at 6 years old the greatest increase in weight to height relation (relative obesity) was seen in children who experienced the greatest exposures to insulin in uterus (as judged by amniotic fluid insulin concentration) [197].

Leptin is also implicated in programming obesity. In humans, leptin is increased in OP and maternal diabetes and is reduced in intrauterine growth restriction [227]. Although the placental transfer of leptin has been demonstrated in vivo [228], it is believed that umbilical blood level of this circulating peptide is a marker of neonatal adiposity more than a relevant modulator of fetal growth [227]. Additionally, several inflammatory cytokines levels are elevated in obese pregnant women [229], changes that are proposed as potential mediators of metabolic programming. Thus, altered metabolic phenotypes, such as obesity and insulin resistance seen in offspring in OP, could partially be explained by the involvement of multiple mediators. Probably, a multifactorial contribution of nutrient- (e.g., D-glucose, fatty acids, amino acids) and hormone- (e.g., insulin, leptin) triggered signals between the obese mother and the developing fetus would better describe the involved mechanisms. Recent studies suggest a strict metabolic control of the mother with GDM in order to overcome the adverse effects of this pathology on the fetal outcome [46, 230-232]. However, adverse effects of GDM environment on fetal tissues persist in time, and multiple studies show increased risk to develop metabolic syndrome in offspring of GDM pregnancies [70, 169, 192]. More recently it was shown that individuals born from GDM pregnancies are prone to develop obesity and Dglucose intolerance compared with offspring from normal pregnancies [198, 199]. However, further research is needed to understand the specific mechanisms of metabolic programming in response to altered intrauterine environment derived from OP and GDM.

\section{Concluding Remarks}

Fetoplacental endothelial dysfunction is a common characteristic of several diseases in pregnancy limiting the function of the placenta vasculature leading to altered fetal growth and development. These phenomena involve altered capacity of one of the essential functions of the endothelium, that is, the synthesis of vasoactive molecules, including NO. It is now established that GDM and OP are pathological conditions altering hCAT-mediated L-arginine transport and eNOS-synthesis of NO (i.e., the "endothelial L-arginine/NO signalling pathway”) in the human fetoplacental vasculature. This phenomenon results in abnormal function of the endothelial L-arginine/NO signalling pathway leading to altered vascular reactivity and changes in umbilical vessels blood flow from and to the fetus with serious consequences on its growth. Abnormalities in the endothelial Larginine/NO signalling pathway are also dependent of several 
regulatory mechanisms, including up-regulation caused by activation of $\mathrm{A}_{2 \mathrm{~A}}$-adenosine receptors in the micro- and macrovasculature of the human placenta in GDM (and perhaps in OP) due to accumulation of extracellular adenosine resulting from reduced hENT expression and activity. Interestingly, GDM pregnancies course with dyslipidaemia (hypertriglyceridemia and hypercholesterolemia) and a pathological link between this condition and development of CVD later in life is likely. A proper management of GDM and OP would be of benefit for the actual newborn's health condition and is crucial for the developing of diseases in the adulthood. Altered function of fetal endothelium at birth is a "metabolic altered state" associated with GDM and OP. We hypothesize that this phenomenon is a potential characteristic (or "at birth metabolic marker") that could be considered as predictor of diseases of the adulthood (e.g., CVD, obesity, diabetes mellitus, metabolic syndrome) resulting from a programmed state due to diseases of pregnancy.

\section{Conflict of Interests}

Authors declare that they have no conflict of interest.

\section{Acknowledgments}

This research supported by Fondo Nacional de Desarrollo Científico y Tecnológico (FONDECYT 1110977, 1080534, 11110059), Chile, Programa de Investigación Interdisciplinario (PIA) from Comisión Nacional de Investigación en Ciencia y Tecnología (CONICYT) (Anillos ACT-73), Chile, and Dirección de Investigación (DI-4061-08, DI-340-09, VRA-2009) and Vicerrectoría Académica (Anillos ACT-73 MA Ramírez Postdoctoral Research Associate at CMPL-PRL, Pontificia Universidad Católica de Chile) from Universidad de Antofagasta, Chile. Authors thank Mrs. Ninoska Muñoz for excellent secretarial assistance and the personnel of the Hospital Clínico Pontificia Universidad Católica de Chile labour ward for supply of placentas.

\section{References}

[1] L. Sobrevia and P. Casanello, "Placenta," in Obstetricia, A. Pérez-Sánchez and E. Donoso-Siña, Eds., pp. 136-176, Mediterráneo, Santiago, Chile, 2011.

[2] P. Casanello, C. Escudero, and L. Sobrevia, "Equilibrative nucleoside (ENTs) and cationic amino acid (CATS) transporters: implications in foetal endothelial dysfunction in human pregnancy diseases," Current Vascular Pharmacology, vol. 5, no. 1, pp. 69-84, 2007.

[3] L. Myatt, "Review: reactive oxygen and nitrogen species and functional adaptation of the placenta," Placenta, vol. 31, pp. S66-S69, 2010.

[4] L. J. Ignarro and C. Napoli, "Novel features of nitric oxide, endothelial nitric oxide synthase, and atherosclerosis," Current Diabetes Reports, vol. 5, no. 1, pp. 17-23, 2005.

[5] S. Moncada and E. A. Higgs, "The discovery of nitric oxide and its role in vascular biology," British Journal of Pharmacology, vol. 147, supplement 1, pp. S193-S201, 2006.

[6] F. Westermeier, C. Puebla, J. L. Vega et al., "Equilibrative nucleoside transporters in fetal endothelial dysfunction in diabetes mellitus and hyperglycaemia," Current Vascular Pharmacology, vol. 7, no. 4, pp. 435-449, 2009.

[7] F. Westermeier, C. Salomón, M. González et al., "Insulin restores gestational diabetes mellitus-reduced adenosine transport involving differential expression of insulin receptor isoforms in human umbilical vein endothelium," Diabetes, vol. 60, no. 6, pp. 1677-1687, 2011.

[8] M. A. Read, I. M. Leitch, W. B. Giles, A. M. Bisits, A. L. Boura, and W. A. Walters, "U46619-mediated vasoconstriction of the fetal placental vasculature in vitro in normal and hypertensive pregnancies," Journal of Hypertension, vol. 17, no. 3, pp. 389-396, 1999.

[9] H. K. Eltzschig, "Adenosine: an old drug newly discovered," Anesthesiology, vol. 111, no. 4, pp. 904-915, 2009.

[10] D. J. Barker, "Fetal programming of coronary heart disease," Trends in Endocrinology and Metabolism, vol. 13, no. 9, pp. 364-368, 2002.

[11] K. L. Thornburg, P. F. O’Tierney, and S. Louey, "Review: the placenta is a programming agent for cardiovascular disease," Placenta, vol. 31, pp. S54-S59, 2010.

[12] K. D. Bruce and M. A. Hanson, "The developmental origins, mechanisms, and implications of metabolic syndrome," Journal of Nutrition, vol. 140, no. 3, pp. 648-652, 2010.

[13] P. M. Catalano, L. Presley, J. Minium, and S. Hauguel de Mouzon, "Fetuses of obese mothers develop insulin resistance in utero," Diabetes Care, vol. 32, no. 6, pp. 10761080, 2009.

[14] R. H. Jones and S. E. Ozanne, "Intra-uterine origins of type 2 diabetes," Archives of Physiology and Biochemistry, vol. 113, no. 1, pp. 25-29, 2007.

[15] C. L. Wei, W. M. Hon, K. H. Lee, and H. E. Khoo, "Chronic administration of aminoguanidine reduces vascular nitric oxide production and attenuates liver damage in bile ductligated rats," Liver International, vol. 25, no. 3, pp. 647-656, 2005.

[16] L. Sobrevia, F. Abarzúa, J. K. Nien et al., "Review: differential placental macrovascular and microvascular endothelial dysfunction in gestational diabetes," Placenta, vol. 25, pp. S159S164, 2011.

[17] C. Escudero and L. Sobrevia, "A hypothesis for preeclampsia: adenosine and inducible nitric oxide synthase in human placental microvascular endothelium," Placenta, vol. 29, no. 6, pp. 469-483, 2008.

[18] R. M. Barbosa, C. F. Lourenço, R. M. Santos et al., "Chapter 20 in vivo real-time measurement of nitric oxide in anesthetized rat brain," Methods in Enzymology, vol. 441, pp. 351-367, 2008.

[19] S. B. Fox and T. Y. Khong, "Lack of innervation of human umbilical cord. An immunohistological and histochemical study," Placenta, vol. 11, no. 1, pp. 59-62, 1990.

[20] J. Deanfield, A. Donald, C. Ferri et al., "Endothelial function and dysfunction. Part I: methodological issues for assessment in the different vascular beds: a statement by the working group on endothelin and endothelial factors of the European society of hypertension," Journal of Hypertension, vol. 23, no. 1, pp. 7-17, 2005.

[21] A. S. Wierzbicki, P. J. Chowienczyk, J. R. Cockcroft et al., "Cardiovascular risk factors and endothelial dysfunction," Clinical Science, vol. 107, no. 6, pp. 609-615, 2004.

[22] D. Versari, E. Daghini, A. Virdis, L. Ghiadoni, and S. Taddei, "Endothelium-dependent contractions and endothelial dysfunction in human hypertension," British Journal of Pharmacology, vol. 157, no. 4, pp. 527-536, 2009. 
[23] P. Libby, P. M. Ridker, and G. K. Hansson, "Progress and challenges in translating the biology of atherosclerosis," Nature, vol. 473, no. 7347, pp. 317-325, 2011.

[24] A. Avogaro, G. P. Fadini, A. Gallo, E. Pagnin, and S. de Kreutzenberg, "Endothelial dysfunction in type 2 diabetes mellitus," Nutrition, Metabolism and Cardiovascular Diseases, vol. 16, supplement 1, pp. S39-S45, 2006.

[25] Z. Cheng, X. Yang, and H. Wang, "Hyperhomocysteinemia and endothelial dysfunction," Current Hypertension Reviews, vol. 5, no. 2, pp. 158-165, 2009.

[26] T. Nakagawa, K. Tanabe, B. P. Croker et al., "Endothelial dysfunction as a potential contributor in diabetic nephropathy," Nature Reviews Nephrology, vol. 7, no. 1, pp. 36-44, 2011.

[27] K. Enomoto, H. Yamabe, K. Toyama et al., "Improvement effect on endothelial function in patients with congestive heart failure treated with cardiac resynchronization therapy," Journal of Cardiology, vol. 58, no. 1, pp. 69-73, 2011.

[28] A. A. Ogonowski, W. H. Kaesemeyer, L. Jin, V. Ganapathy, F. H. Leibach, and R. W. Caldwell, "Effects of NO donors and synthase agonists on endothelial cell uptake of L-Arg and superoxide production," American Journal of Physiology, vol. 278, no. 1, pp. C136-C143, 2000.

[29] E. I. Closs, J. S. Scheld, M. Sharafi, and U. Förstermann, "Substrate supply for nitric-oxide synthase in macrophages and endothelial cells: role of cationic amino acid transporters," Molecular Pharmacology, vol. 57, no. 1, pp. 68-74, 2000.

[30] L. Sobrevia and M. González, "A role for insulin on Larginine transport in fetal endothelial dysfunction in hyperglycaemia," Current Vascular Pharmacology, vol. 7, no. 4, pp. 467-474, 2009.

[31] R. Devés and C. A. Boyd, "Transporters for cationic amino acids in animal cells: discovery, structure, and function," Physiological Reviews, vol. 78, no. 2, pp. 487-545, 1998.

[32] G. E. Mann, D. L. Yudilevich, and L. Sobrevia, "Regulation of amino acid and glucose transporters in endothelial and smooth muscle cells," Physiological Reviews, vol. 83, no. 1, pp. 183-252, 2003.

[33] M. González, V. Gallardo, N. Rodríguez et al., "Insulinstimulated L-arginine transport requires SLC7A1 gene expression and is associated with human umbilical vein relaxation," Journal of Cellular Physiology, vol. 226, no. 11, pp. 2916-2924, 2011.

[34] F. Verrey, E. I. Closs, C. A. Wagner, M. Palacin, H. Endou, and Y. Kanai, "CATs and HATs: the SLC7 family of amino acid transporters," Pflügers Archiv European Journal of Physiology, vol. 447, no. 5, pp. 532-542, 2004.

[35] C. Flores, S. Rojas, C. Aguayo et al., "Rapid stimulation of L-arginine transport by D-glucose involves $\mathrm{p} 42 / 44^{\mathrm{mapk}}$ and nitric oxide in human umbilical vein endothelium," Circulation Research, vol. 92, no. 1, pp. 64-72, 2003.

[36] J. F. Dye, S. Vause, T. Johnston et al., "Characterization of cationic amino acid transporters and expression of endothelial nitric oxide synthase in human placental microvascular endothelial cells," The FASEB Journal, vol. 18, no. 1, pp. 125127, 2004.

[37] E. Tsitsiou, C. P. Sibley, S. W. D'Souza, O. Catanescu, D. W. Jacobsen, and J. D. Glazier, "Homocysteine transport by systems $\mathrm{L}, \mathrm{A}$ and $\mathrm{y}^{+} \mathrm{L}$ across the microvillous plasma membrane of human placenta," Journal of Physiology, vol. 587, no. 16, pp. 4001-4013, 2009.

[38] Y. Arancibia-Garavilla, F. Toledo, P. Casanello, and L. Sobrevia, "Nitric oxide synthesis requires activity of the cationic and neutral amino acid transport system $\mathrm{y}^{+} \mathrm{L}$ in human umbilical vein endothelium," Experimental Physiology, vol. 88, no. 6, pp. 699-710, 2003.

[39] G. Vásquez, F. Sanhueza, R. Vásquez et al., "Role of adenosine transport in gestational diabetes-induced L-arginine transport and nitric oxide synthesis in human umbilical vein endothelium," Journal of Physiology, vol. 560, no. 1, pp. 111122, 2004.

[40] M. Pastor-Anglada, B. Dérijard, and F. J. Casado, "Mechanisms implicated in the response of system a to hypertonic stress and amino acid deprivation still can be different," The Journal of General Physiology, vol. 125, no. 1, pp. 41-42, 2005.

[41] S. A. Baldwin, P. R. Beal, S. Y. Yao, A. E. King, C. E. Cass, and J. D. Young, "The equilibrative nucleoside transporter family, SLC29," Pflügers Archiv European Journal of Physiology, vol. 447, no. 5, pp. 735-743, 2004.

[42] C. Aguayo, J. Casado, M. González et al., "Equilibrative nucleoside transporter 2 is expressed in human umbilical vein endothelium, but is not involved in the inhibition of adenosine transport induced by hyperglycaemia," Placenta, vol. 26, no. 8-9, pp. 641-653, 2005.

[43] P. Casanello, A. Torres, F. Sanhueza et al., "Equilibrative nucleoside transporter 1 expression is downregulated by hypoxia in human umbilical vein endothelium," Circulation Research, vol. 97, no. 1, pp. 16-24, 2005.

[44] C. Salomón, F. Westermeier, P. Casanello, and L. Sobrevia, "Differential modulation of insulin receptor isoforms expression and NOS activity by insulin in human placenta microvascular endothelial cells from gestational diabetes," Placenta, vol. 31, 2010.

[45] K. Engel, M. Zhou, and J. Wang, "Identification and characterization of a novel monoamine transporter in the human brain," Journal of Biological Chemistry, vol. 279, no. 48, pp. 50042-50049, 2004.

[46] K. Barnes, H. Dobrzynski, S. Foppolo et al., "Distribution and functional characterization of equilibrative nucleoside transporter-4, a novel cardiac adenosine transporter activated at acidic pH," Circulation Research, vol. 99, no. 5, pp. 510-519, 2006.

[47] E. Guzmán-Gutiérrez, F. Abarzúa, C. Belmar et al., "Functional link between adenosine and insulin: a hypothesis for fetoplacental vascular endothelial dysfunction in gestational diabetes," Current Vascular Pharmacology, vol. 9, no. 6, pp. 750-752, 2011.

[48] R. San Martín and L. Sobrevia, "Gestational diabetes and the adenosine/L-arginine/nitric oxide (ALANO) pathway in human umbilical vein endothelium," Placenta, vol. 27, no. 1, pp. 1-10, 2006.

[49] C. Escudero, P. Casanello, and L. Sobrevia, "Human equilibrative nucleoside transporters 1 and 2 may be differentially modulated by $\mathrm{A} 2 \mathrm{~B}$ adenosine receptors in placenta microvascular endothelial cells from pre-eclampsia," Placenta, vol. 29, no. 9, pp. 816-825, 2008.

[50] J. M. Marshall, "The roles of adenosine and related substances in exercise hyperaemia," Journal of Physiology, vol. 583, no. 3, pp. 835-845, 2007.

[51] M. Farías, C. Puebla, F. Westermeier et al., "Nitric oxide reduces SLC29A1 promoter activity and adenosine transport involving transcription factor complex hCHOP-C/EBP $\alpha$ in human umbilical vein endothelial cells from gestational diabetes," Cardiovascular Research, vol. 86, no. 1, pp. 45-54, 2010.

[52] A. Pandolfi and N. Di Pietro, "High glucose, nitric oxide, and adenosine: a vicious circle in chronic hyperglycaemia?" Cardiovascular Research, vol. 86, no. 1, pp. 9-11, 2010. 
[53] American Diabetes Association, "Diagnosis and classification of diabetes mellitus," Diabetes Care, vol. 34, supplement 1, pp. S62-S69, 2011.

[54] J. L. Nold and M. K. Georgieff, "Infants of diabetic mothers," Pediatric Clinics of North America, vol. 51, no. 3, pp. 619-637, 2004.

[55] M. F. Greene and C. G. Solomon, "Gestational diabetes mellitus-time to treat," New England Journal of Medicine, vol. 352, no. 24, pp. 2544-2546, 2005.

[56] G. Desoye and S. Hauguel-De Mouzon, "The human placenta in gestational diabetes mellitus: the insulin and cytokine network," Diabetes Care, vol. 30, supplement 2, pp. S120-S126, 2007.

[57] L. Leach, "Placental vascular dysfunction in diabetic pregnancies: intimations of fetal cardiovascular disease?" Microcirculation, vol. 18, no. 4, pp. 263-269, 2011.

[58] R. Figueroa, E. Martinez, R. P. Fayngersh, N. Tejani, K. M. Mohazzab-H, and M. S. Wolin, "Alterations in relaxation to lactate and $\mathrm{H}_{2} \mathrm{O}_{2}$ in human placental vessels from gestational diabetic pregnancies," American Journal of Physiology, vol. 278, no. 3, pp. H706-H713, 2000.

[59] M. Farías, R. San Martín, C. Puebla et al., "Nitric oxide reduces adenosine transporter ENT1 gene (SLC29A1) promoter activity in human fetal endothelium from gestational diabetes," Journal of Cellular Physiology, vol. 208, no. 2, pp. 451-460, 2006.

[60] M. González, C. Flores, J. D. Pearson, P. Casanello, and L. Sobrevia, "Cell signalling-mediating insulin increase of mRNA expression for cationic amino acid transporters-1 and -2 and membrane hyperpolarization in human umbilical vein endothelial cells," Pflügers Archiv European Journal of Physiology, vol. 448, no. 4, pp. 383-394, 2004.

[61] M. Srinivasan, P. Herrero, J. B. McGill et al., "The effects of plasma insulin and glucose on myocardial blood flow in patients with type 1 diabetes mellitus," Journal of the American College of Cardiology, vol. 46, no. 1, pp. 42-48, 2005.

[62] L. Sobrevia, S. M. Jarvis, and D. L. Yudilevich, "Adenosine transport in cultured human umbilical vein endothelial cells is reduced in diabetes," American Journal of Physiology, vol. 267, no. 1, pp. C39-C47, 1994.

[63] M. Farías, Intracellular signalling in the reduced expression and activity of the equilibrative nucleoside transporter 1 ( $h E N T 1$ ) in human umbilical vein endothelium from gestational diabetes mellitus, Ph.D. thesis, Pontificia Universidad Católica de Chile, 2008.

[64] L. Sobrevia, C. Puebla, F. Farías, and P. Casanello, "Role of equilibrative nucleoside transporters in fetal endothelial dysfunction in gestational diabetes," in Membrane Transporters and Receptors in Disease, L. Sobrevia and P. Casanello, Eds., pp. 1-25, Research Signpost, Kerala, India, 2009.

[65] N. M. Nivillac, K. Wasal, D. F. Villani, Z. Naydenova, W. J. Hanna, and I. R. Coe, "Disrupted plasma membrane localization and loss of function reveal regions of human equilibrative nucleoside transporter 1 involved in structural integrity and activity," Biochimica et Biophysica Acta, vol. 1788, no. 10, pp. 2326-2334, 2009.

[66] N. M. Nivillac, J. Bacani, and I. R. Coe, "The life cycle of human equilibrative nucleoside transporter 1: from ER export to degradation," Experimental Cell Research, vol. 317, no. 11, pp. 1567-1579, 2011.

[67] Y. Yoneyama, R. Sawa, S. Suzuki et al., "Regulation of plasma adenosine levels in normal pregnancy," Gynecologic and Obstetric Investigation, vol. 53, no. 2, pp. 71-74, 2002.
[68] Y. Yoneyama, S. Suzuki, R. Sawa, K. Yoneyama, G. G. Power, and T. Araki, "Increased plasma adenosine concentrations and the severity of preeclampsia," Obstetrics and Gynecology, vol. 100, no. 6, pp. 1266-1270, 2002.

[69] M. F. Ethier, V. Chander, and J. G. Dobson Jr., "Adenosine stimulates proliferation of human endothelial cells in culture," American Journal of Physiology, vol. 265, no. 1, pp. H131-H138, 1993.

[70] G. Muñoz, R. San Martín, M. Farías et al., "Insulin restores glucose inhibition of adenosine transport by increasing the expression and activity of the equilibrative nucleoside transporter 2 in human umbilical vein endothelium," Journal of Cellular Physiology, vol. 209, no. 3, pp. 826-835, 2006.

[71] M. J. Romero, D. H. Platt, H. E. Tawfik et al., "Diabetesinduced coronary vascular dysfunction involves increased arginase activity," Circulation Research, vol. 102, no. 1, pp. 95-102, 2008.

[72] S. M. Morris Jr., "Recent advances in arginine metabolism: roles and regulation of the arginases," British Journal of Pharmacology, vol. 157, no. 6, pp. 922-930, 2009.

[73] ATP III, "Third report of the national cholesterol education program (NCEP) expert panel on detection, evaluation, and treatment of high blood cholesterol in adults (Adult Treatment Panel III) final report," Circulation, vol. 106, no. 25, pp. 3143-3421, 2002.

[74] J. Davignon and P. Ganz, "Role of endothelial dysfunction in atherosclerosis," Circulation, vol. 109, no. 23, pp. III27-III32, 2004.

[75] V. L. Roger, A. S. Go, D. M. Lloyd-Jones et al., "Heart disease and stroke statistics-2011 update: a report from the American Heart Association," Circulation, vol. 123, pp. e18-e209, 2011.

[76] B. J. Arsenault, S. M. Boekholdt, and J. J. Kastelein, "Lipid parameters for measuring risk of cardiovascular disease," Nature Reviews Cardiology, vol. 8, no. 4, pp. 197-206, 2011.

[77] C. M. Boney, A. Verma, R. Tucker, and B. R. Vohr, "Metabolic syndrome in childhood: association with birth weight, maternal obesity, and gestational diabetes mellitus," Pediatrics, vol. 115, no. 3, pp. e290-e296, 2005.

[78] T. D. Clausen, E. R. Mathiesen, T. Hansen et al., "Overweight and the metabolic syndrome in adult offspring of women with diet-treated gestational diabetes mellitus or type 1 diabetes," Journal of Clinical Endocrinology and Metabolism, vol. 94, no. 7, pp. 2464-2470, 2009.

[79] T. R. Moore, "Fetal exposure to gestational diabetes contributes to subsequent adult metabolic syndrome," American Journal of Obstetrics and Gynecology, vol. 202, no. 6, pp. 643649, 2010.

[80] B. Isomaa, P. Almgren, T. Tuomi et al., "Cardiovascular morbidity and mortality associated with the metabolic syndrome," Diabetes Care, vol. 24, no. 4, pp. 683-689, 2001.

[81] G. M. Egeland and S. J. Meltzer, "Following in mother's footsteps? Mother-daughter risks for insulin resistance and cardiovascular disease 15 years after gestational diabetes," Diabetic Medicine, vol. 27, no. 3, pp. 257-265, 2010.

[82] J. Pirkola, M. Vääräsmäki, M. Ala-Korpela et al., "Lowgrade, systemic inflammation in adolescents: association with early-life factors, gender, and lifestyle," American Journal of Epidemiology, vol. 171, no. 1, pp. 72-82, 2010.

[83] S. Mottillo, K. B. Filion, J. Genest et al., "The metabolic syndrome and cardiovascular risk: a systematic review and meta-analysis," Journal of the American College of Cardiology, vol. 56, no. 14, pp. 1113-1132, 2010. 
[84] E. A. Reece, "The fetal and maternal consequences of gestational diabetes mellitus," Journal of Maternal-Fetal and Neonatal Medicine, vol. 23, no. 3, pp. 199-203, 2010.

[85] A. Basaran, "Pregnancy-induced hyperlipoproteinemia: review of the literature," Reproductive Sciences, vol. 16, no. 5, pp. 431-437, 2009.

[86] E. Herrera and H. Ortega-Senovilla, "Disturbances in lipid metabolism in diabetic pregnancy — are these the cause of the problem?" Best Practice \& Research Clinical Endocrinology \& Metabolism, vol. 24, no. 4, pp. 515-525, 2010.

[87] N. F. Butte, "Carbohydrate and lipid metabolism in pregnancy: normal compared with gestational diabetes mellitus," American Journal of Clinical Nutrition, vol. 71, no. 5, pp. 1256-1261, 2000.

[88] A. Zawiejska, E. Wender-Ozegowska, J. Brazert, and K. Sodowski, "Components of metabolic syndrome and their impact on fetal growth in women with gestational diabetes mellitus," Journal of Physiology and Pharmacology, vol. 59, supplement 4, pp. S5-S18, 2008.

[89] G. H. Son, J. Y. Kwon, Y. H. Kim, and Y. W. Park, "Maternal serum triglycerides as predictive factors for large-for- gestational age newborns in women with gestational diabetes mellitus," Acta Obstetricia et Gynecologica Scandinavica, vol. 89, no. 5, pp. 700-704, 2010.

[90] C. J. Nolan, S. F. Riley, M. T. Sheedy, J. E. Walstab, and N. A. Bescher, "Maternal serum triglyceride, glucose tolerance, and neonatal birth weight ratio in pregnancy: a study within a racially heterogeneous population," Diabetes Care, vol. 18, no. 12, pp. 1550-1556, 1995.

[91] M. Kitajima, S. Oka, I. Yasuhi, M. Fukuda, Y. Rii, and T. Ishimaru, "Maternal serum triglyceride at 24-32 weeks' gestation and newborn weight in nondiabetic women with positive diabetic screens," Obstetrics and Gynecology, vol. 97, no. 5, pp. 776-780, 2001.

[92] U. M. Schaefer-Graf, K. Graf, I. Kulbacka et al., "Maternal lipids as strong determinants of fetal environment and growth in pregnancies with gestational diabetes mellitus," Diabetes Care, vol. 31, no. 9, pp. 1858-1863, 2008.

[93] C. Marseille-Tremblay, M. Ethier-Chiasson, J. C. Forest et al., "Impact of maternal circulating cholesterol and gestational diabetes mellitus on lipid metabolism in human term placenta," Molecular Reproduction and Development, vol. 75, no. 6, pp. 1054-1062, 2008.

[94] A. L. Magnusson, I. J. Waterman, M. Wennergren, T. Jansson, and T. L. Powell, "Triglyceride hydrolase activities and expression of fatty acid binding proteins in the human placenta in pregnancies complicated by intrauterine growth restriction and diabetes," Journal of Clinical Endocrinology and Metabolism, vol. 89, no. 9, pp. 4607-4614, 2004.

[95] C. M. Scifres, B. Chen, D. M. Nelson, and Y. Sadovsky, "Fatty acid binding protein 4 regulates intracellular lipid accumulation in human trophoblasts," Journal of Clinical Endocrinology and Metabolism, vol. 96, no. 7, pp. E1083E1091, 2011.

[96] T. Radaelli, J. Lepercq, A. Varastehpour, S. Basu, P. M. Catalano, and S. Hauguel-De Mouzon, "Differential regulation of genes for fetoplacental lipid pathways in pregnancy with gestational and type 1 diabetes mellitus," American Journal of Obstetrics and Gynecology, vol. 201, no. 2, pp. 209.e1209.e10, 2009.

[97] P. Brizzi, G. Tonolo, F. Esposito et al., "Lipoprotein metabolism during normal pregnancy," American Journal of Obstetrics and Gynecology, vol. 181, no. 2, pp. 430-434, 1999.
[98] H. J. Avis, B. A. Hutten, M. T. Twickler et al., "Pregnancy in women suffering from familial hypercholesterolemia: a harmful period for both mother and newborn?" Current Opinion in Lipidology, vol. 20, no. 6, pp. 484-490, 2009.

[99] A. Montes, C. E. Walden, and R. H. Knopp, "Physiologic and supraphysiologic increases in lipoprotein lipids and apoproteins in late pregnancy and postpartum. Possible markers for the diagnosis of "prelipemia"," Arteriosclerosis, vol. 4, no. 4, pp. 407-417, 1984.

[100] C. Napoli, F. P. D’Armiento, F. P. Mancini et al., "Fatty streak formation occurs in human fetal aortas and is greatly enhanced maternal, hypercholesterolemia. Intimal accumulation of low density lipoprotein and its oxidation precede monocyte recruitment into early atheroeclerotic lesions," Journal of Clinical Investigation, vol. 100, no. 11, pp. 26802690, 1997.

[101] C. Napoli, C. K. Glass, J. L. Witztum, R. Deutsch, F. P. D'Armiento, and W. Palinski, "Influence of maternal hypercholesterolaemia during pregnancy on progression of early atherosclerotic lesions in childhood: Fate of Early Lesions in Children (FELIC) study," The Lancet, vol. 354, no. 9186, pp. 1234-1241, 1999.

[102] K. P. Battaile and R. D. Steiner, "Smith-Lemli-Opitz syndrome: the first malformation syndrome associated with defective cholesterol synthesis," Molecular Genetics and Metabolism, vol. 71, no. 1-2, pp. 154-162, 2000.

[103] C. Wadsack, A. Hammer, S. Levak-Frank et al., "Selective cholesteryl ester uptake from high density lipoprotein by human first trimester and term villous trophoblast cells," Placenta, vol. 24, no. 2-3, pp. 131-143, 2003.

[104] K. T. Jenkins, L. S. Merkens, M. R. Tubb et al., "Enhanced placental cholesterol efflux by fetal HDL in Smith-LemliOpitz syndrome," Molecular Genetics and Metabolism, vol. 94, no. 2, pp. 240-247, 2008.

[105] J. Stefulj, U. Panzenboeck, T. Becker et al., "Human endothelial cells of the placental barrier efficiently deliver cholesterol to the fetal circulation via ABCA1 and ABCG1," Circulation Research, vol. 104, no. 5, pp. 600-608, 2009.

[106] L. A. Woollett, "Review: transport of maternal cholesterol to the fetal circulation," Placenta, vol. 32, supplement 2, pp. S218-S221, 2011.

[107] S. H. Badruddin, R. Lalani, M. Khurshid, A. Molla, R. Qureshi, and M. A. Khan, "Serum cholesterol in neonates and their mothers. A pilot study," Journal of the Pakistan Medical Association, vol. 40, no. 5, pp. 108-109, 1990.

[108] A. Liguori, F. P. D’Armiento, A. Palagiano et al., "Effect of gestational hypercholesterolaemia on omental vasoreactivity, placental enzyme activity and transplacental passage of normal and oxidised fatty acids," An International Journal of Obstetrics and Gynaecology, vol. 114, no. 12, pp. 1547-1556, 2007.

[109] W. Palinski and C. Napoli, "The fetal origins of atherosclerosis: maternal hypercholesterolemia, and cholesterol-lowering or antioxidant treatment during pregnancy influence in utero programming and postnatal susceptibility to atherogenesis," The FASEB Journal, vol. 16, no. 11, pp. 1348-1360, 2002.

[110] M. R. Skilton, "Intrauterine risk factors for precocious atherosclerosis," Pediatrics, vol. 121, no. 3, pp. 570-574, 2008.

[111] C. Napoli, L. O. Lerman, F. de Nigris, M. Gossl, M. L. Balestrieri, and A. Lerman, "Rethinking primary prevention of atherosclerosis-related diseases," Circulation, vol. 114, no. 23, pp. 2517-2527, 2006.

[112] C. Napoli and W. Palinski, "Maternal hypercholesterolemia during pregnancy influences the later development of 
atherosclerosis: clinical and pathogenic implications," European Heart Journal, vol. 22, no. 1, pp. 4-9, 2001.

[113] W. Palinski, E. Nicolaides, A. Liguori, and C. Napoli, "Influence of maternal dysmetabolic conditions during pregnancy on cardiovascular disease," Journal of Cardiovascular Translational Research, vol. 2, no. 3, pp. 277-285, 2009.

[114] C. Napoli and F. Cacciatore, "Novel pathogenic insights in the primary prevention of cardiovascular disease," Progress in Cardiovascular Diseases, vol. 51, no. 6, pp. 503-523, 2009.

[115] A. Liguori, F. P. D’Armiento, A. Palagiano, W. Palinski, and C. Napoli, "Maternal C-reactive protein and developmental programming of atherosclerosis," American Journal of Obstetrics and Gynecology, vol. 198, no. 3, pp. 281.e1-281.e5, 2008.

[116] P. A. Stapleton, A. G. Goodwill, M. E. James, R. W. Brock, and J. C. Frisbee, "Hypercholesterolemia and microvascular dysfunction: interventional strategies," Journal of Inflammation, vol. 7, article 54, 2010.

[117] J. A. Joles, "Crossing borders: linking environmental and genetic developmental factors," Microcirculation, vol. 18, no. 4, pp. 298-303, 2011.

[118] E. Koklu, M. Akcakus, S. Kurtoglu et al., "Aortic intimamedia thickness and lipid profile in macrosomic newborns," European Journal of Pediatrics, vol. 166, no. 4, pp. 333-338, 2007.

[119] A. Leiva, E. Guzmán-Gutiérrez, F. Abarzúa, P. Casanello, and L. Sobrevia, "Maternal supraphysiologicalhypercholesterolemia leads to reduced endothelium-dependent vasodilation of umbilical vein and increased L-arginine transport in HUVEC," Journal of Developmental Origins of Health and Disease, vol. 2, supplement 1, p. S95, 2011.

[120] M. González, E. Muñoz, C. Puebla et al., "Maternal and fetal metabolic dysfunction in pregnancy diseases associated with vascular oxidative and nitrative stress," in The Molecular Basis for Origin of Fetal Congenital Abnormalities and Maternal Health: An overview of Association with Oxidative Stress, B. M. Matata and M. Elahi, Eds., Bentham, USA, 2011.

[121] Y. Aggoun, I. Szezepanski, and D. Bonnet, "Noninvasive assessment of arterial stiffness and risk of atherosclerotic events in children," Pediatric Research, vol. 58, no. 2, pp. 173178, 2005.

[122] S. Riggio, G. Mandraffino, M. A. Sardo et al., "Pulse wave velocity and augmentation index, but not intimamedia thickness, are early indicators of vascular damage in hypercholesterolemic children," European Journal of Clinical Investigation, vol. 40, no. 3, pp. 250-257, 2010.

[123] M. A. Creager, J. P. Cooke, M. E. Mendelsohn et al., "Impaired vasodilation of forearm resistance vessels in hypercholesterolemic humans," Journal of Clinical Investigation, vol. 86, no. 1, pp. 228-234, 1990.

[124] K. Egashira, T. Inou, Y. Hirooka et al., "Impaired coronary blood flow response to acetylcholine in patients with coronary risk factors and proximal atherosclerotic lesions," Journal of Clinical Investigation, vol. 91, no. 1, pp. 29-37, 1993.

[125] T. Münzel, C. Sinning, F. Post, A. Warnholtz, and E. Schulz, "Pathophysiology, diagnosis and prognostic implications of endothelial dysfunction," Annals of Medicine, vol. 40, no. 3, pp. 180-196, 2008.

[126] S. Kawashima and M. Yokoyama, "Dysfunction of endothelial nitric oxide synthase and atherosclerosis," Arteriosclerosis, Thrombosis, and Vascular Biology, vol. 24, no. 6, pp. 9981005, 2004.

[127] I. F. Schwartz, M. Ingbir, T. Chernichovski et al., "Arginine uptake is attenuated, through post-translational regulation of cationic amino acid transporter-1, in hyperlipidemic rats," Atherosclerosis, vol. 194, no. 2, pp. 357-363, 2007.

[128] W. Z. Zhang, K. Venardos, S. Finch, and D. M. Kaye, "Detrimental effect of oxidized LDL on endothelial arginine metabolism and transportation," International Journal of Biochemistry and Cell Biology, vol. 40, pp. 920-928, 2008.

[129] J. K. Liao, W. S. Shin, W. Y. Lee, and S. L. Clark, "Oxidized low-density lipoprotein decreases the expression of endothelial nitric oxide synthase," Journal of Biological Chemistry, vol. 270, no. 1, pp. 319-324, 1995.

[130] F. Vidal, C. Colomé, J. Martínez-González, and L. Badimon, "Atherogenic concentrations of native low-density lipoproteins down- regulate nitric-oxide-synthase mRNA and protein levels in endothelial cells," European Journal of Biochemistry, vol. 252, no. 3, pp. 378-384, 1998.

[131] A. Jiménez, M. M. Arriero, A. López-Blaya et al., "Regulation of endothelial nitric oxide synthase expression in the vascular wall and in mononuclear cells from hypercholesterolemic rabbits," Circulation, vol. 104, no. 15, pp. 1822-1830, 2001.

[132] M. Ozaki, S. Kawashima, T. Yamashita et al., "Overexpression of endothelial nitric oxide synthase accelerates atherosclerotic lesion formation in apoE-deficient mice," Journal of Clinical Investigation, vol. 110, no. 3, pp. 331-340, 2002.

[133] F. T. Tang, Z. Y. Qian, P. Q. Liu et al., "Crocetin improves endothelium-dependent relaxation of thoracic aorta in hypercholesterolemic rabbit by increasing eNOS activity," Biochemical Pharmacology, vol. 72, no. 5, pp. 558-565, 2006.

[134] J. Dulak, M. Polus, I. Guevara, A. Polus, J. Hartwich, and A. Dembińska-Kieć, "Regulation of inducible nitric oxide synthase (iNOS) and GTP cyclohydrolase I (GTP-CH I) gene expression by OX-LDL in rat vascular smooth muscle cells," Journal of Physiology and Pharmacology, vol. 48, no. 4, pp. 689-697, 1997.

[135] J. Dulak, M. Polus, I. Guevara et al., "Oxidized low density lipoprotein inhibits inducible nitric oxide synthase, GTP cyclohydrolase I and transforming growth factor beta gene expression in rat macrophages," Journal of Physiology and Pharmacology, vol. 50, no. 3, pp. 429-441, 1999.

[136] S. Ryoo, C. A. Lemmon, K. G. Soucy et al., "Oxidized low-density lipoprotein-dependent endothelial arginase II activation contributes to impaired nitric oxide signaling," Circulation Research, vol. 99, no. 9, pp. 951-960, 2006.

[137] S. Ryoo, G. Gupta, A. Benjo et al., "Endothelial arginase II: a novel target for the treatment of atherosclerosis," Circulation Research, vol. 102, no. 8, pp. 923-932, 2008.

[138] S. Ryoo, A. Bhunia, F. Chang, A. Shoukas, D. E. Berkowitz, and L. H. Romer, "OxLDL-dependent activation of arginase II is dependent on the LOX-1 receptor and downstream RhoA signaling," Atherosclerosis, vol. 214, no. 2, pp. 279-287, 2011.

[139] D. Spruijt-Metz, "Etiology, treatment, and prevention of obesity in childhood and adolescence: a decade in review," Journal of Research on Adolescence, vol. 21, no. 1, pp. 129-152, 2011.

[140] S. E. Shoelson, L. Herrero, and A. Naaz, "Obesity, Inflammation, and Insulin Resistance," Gastroenterology, vol. 132, no. 6, pp. 2169-2180, 2007.

[141] S. Nishimura, I. Manabe, and R. Nagai, "Adipose tissue inflammation in obesity and metabolic syndrome," Discovery Medicine, vol. 8, no. 41, pp. 55-60, 2009.

[142] M. Tesauro and C. Cardillo, "Obesity, blood vessels and metabolic syndrome," Acta Physiologica, vol. 203, no. 1, pp. 279-286, 2011. 
[143] World Health Organization, "Obesity and Overweight," Fact Sheet $\mathrm{N}^{\circ} 311$, March 2011.

[144] A. A. Hedley, C. L. Ogden, C. L. Johnson, M. D. Carroll, L. R. Curtin, and K. M. Flegal, "Prevalence of overweight and obesity among US children, adolescents, and adults, 19992002," Journal of the American Medical Association, vol. 291, no. 23, pp. 2847-2850, 2004.

[145] A. M. Magarey, L. A. Daniels, T. J. Boulton, and R. A. Cockington, "Predicting obesity in early adulthood from childhood and parental obesity," International Journal of Obesity, vol. 27, no. 4, pp. 505-513, 2003.

[146] S. Danielzik, M. Czerwinski-Mast, K. Langnäse, B. Dilba, and M. J. Müller, "Parental overweight, socioeconomic status and high birth weight are the major determinants of overweight and obesity in 5-7 y-old children: baseline data of the Kiel Obesity Prevention Study (KOPS)," International Journal of Obesity, vol. 28, no. 11, pp. 1494-1502, 2004.

[147] P. J. Salsberry and P. B. Reagan, "Dynamics of early childhood overweight," Pediatrics, vol. 116, no. 6, pp. 1329-1338, 2005.

[148] H. M. Ehrenberg, C. P. Durnwald, P. Catalano, and B. M. Mercer, "The influence of obesity and diabetes on the risk of cesarean delivery," American Journal of Obstetrics and Gynecology, vol. 191, no. 3, pp. 969-974, 2004.

[149] B. Rosenn, "Obesity and diabetes: a recipe for obstetric complications," Journal of Maternal-Fetal and Neonatal Medicine, vol. 21, no. 3, pp. 159-164, 2008.

[150] J. M. Salbaum and C. Kappen, "Diabetic embryopathy: a role for the epigenome?" Birth Defects Research Part A, vol. 91, no. 8, pp. 770-780, 2011.

[151] V. O'Dwyer, N. Farah, C. Fattah, N. O'Connor, M. M. Kennelly, and M. J. Turner, "The risk of caesarean section in obese women analysed by parity," European Journal of Obstetrics Gynecology and Reproductive Biology, vol. 158, no. 1, pp. 28-32, 2011.

[152] J. C. Challier, S. Basu, T. Bintein et al., "Obesity in pregnancy stimulates macrophage accumulation and inflammation in the placenta," Placenta, vol. 29, no. 3, pp. 274-281, 2008.

[153] K. A. Roberts, S. C. Riley, R. M. Reynolds et al., "Placental structure and inflammation in pregnancies associated with obesity," Placenta, vol. 32, no. 3, pp. 247-254, 2011.

[154] L. Higgins, S. L. Greenwood, M. Wareing, C. P. Sibley, and T. A. Mills, "Obesity and the placenta: a consideration of nutrient exchange mechanisms in relation to aberrant fetal growth," Placenta, vol. 32, no. 1, pp. 1-7, 2011.

[155] U. Hiden, I. Lang, N. Ghaffari-Tabrizi, M. Gauster, U. Lang, and G. Desoye, "Insulin action on the human placental endothelium in normal and diabetic pregnancy," Current Vascular Pharmacology, vol. 7, no. 4, pp. 460-466, 2009.

[156] T. Becker, M. J. Vermeulen, P. R. Wyatt, C. Meier, and J. G. Ray, "Maternal obesity and the risk of placental vascular disease," Journal of Obstetrics and Gynaecology Canada, vol. 30, no. 12, pp. 1132-1136, 2008.

[157] F. C. Denison, J. Price, C. Graham, S. Wild, and W. A. Liston, "Maternal obesity, length of gestation, risk of postdates pregnancy and spontaneous onset of labour at term," An International Journal of Obstetrics and Gynaecology, vol. 115, no. 6, pp. 720-725, 2008.

[158] S. Y. Chu, W. M. Callaghan, S. Y. Kim et al., "Maternal obesity and risk of gestational diabetes mellitus," Diabetes Care, vol. 30, no. 8, pp. 2070-2076, 2007.

[159] J. Lepercq, M. Cauzac, N. Lahlou et al., "Overexpression of placental leptin in diabetic pregnancy: a critical role for insulin," Diabetes, vol. 47, no. 5, pp. 847-850, 1998.
[160] M. A. Williams, P. J. Havel, M. W. Schwartz et al., "Preeclampsia disrupts the normal relationship between serum leptin concentrations and adiposity in pregnant women," Paediatric and Perinatal Epidemiology, vol. 13, no. 2, pp. 190204, 1999.

[161] T. Reimer, D. Koczan, B. Gerber, D. Richter, H. J. Thiesen, and K. Friese, "Microarray analysis of differentially expressed genes in placental tissue of pre-eclampsia: up-regulation of obesity-related genes," Molecular Human Reproduction, vol. 8, no. 7, pp. 674-680, 2002.

[162] P. A. Kern, S. Ranganathan, C. Li, L. Wood, and G. Ranganathan, "Adipose tissue tumor necrosis factor and interleukin-6 expression in human obesity and insulin resistance," American Journal of Physiology, vol. 280, no. 5, pp. E745-E751, 2001.

[163] A. D. Pradhan, J. E. Manson, N. Rifai, J. E. Buring, and P. M. Ridker, "C-reactive protein, interleukin 6, and risk of developing type 2 diabetes mellitus," Journal of the American Medical Association, vol. 286, no. 3, pp. 327-334, 2001.

[164] B. Vozarova, C. Weyer, K. Hanson, P. A. Tataranni, C. Bogardus, and R. E. Pratley, "Circulating interleukin-6 in relation to adiposity, insulin action, and insulin secretion," Obesity Research, vol. 9, no. 7, pp. 414-417, 2001.

[165] P. Dandona, R. Weinstock, K. Thusu, E. Abdel-Rahman, A. Aljada, and T. Wadden, "Tumor necrosis factor-alpha in sera of obese patients: fall with weight loss," Journal of Clinical Endocrinology and Metabolism, vol. 83, no. 8, pp. 2907-2910, 1998.

[166] P. Dandona, A. Aljada, and A. Bandyopadhyay, "Inflammation: the link between insulin resistance, obesity and diabetes," Trends in Immunology, vol. 25, no. 1, pp. 4-7, 2004.

[167] S. P. Weisberg, D. McCann, M. Desai, M. Rosenbaum, R. L. Leibel, and A. W. Ferrante Jr., "Obesity is associated with macrophage accumulation in adipose tissue," Journal of Clinical Investigation, vol. 112, no. 12, pp. 1796-1808, 2003.

[168] G. Fantuzzi, "Adipose tissue, adipokines, and inflammation," Journal of Allergy and Clinical Immunology, vol. 115, no. 5, pp. 911-920, 2005.

[169] H. Tilg and A. R. Moschen, "Adipocytokines: mediators linking adipose tissue, inflammation and immunity," Nature Reviews Immunology, vol. 6, no. 10, pp. 772-783, 2006.

[170] K. Meijer, M. de Vries, S. Al-Lahham et al., "Human primary adipocytes exhibit immune cell function: adipocytes prime inflammation independent of macrophages," PLoS One, vol. 6, no. 3, Article ID e17154, 2011.

[171] J. A. Suwaidi, S. Hamasaki, S. T. Higano, R. A. Nishimura, D. R. Holmes, and A. Lerman, "Long-term follow-up of patients with mild coronary artery disease and endothelial dysfunction," Circulation, vol. 101, no. 9, pp. 948-954, 2000.

[172] F. Kim, M. Pham, E. Maloney et al., "Vascular inflammation, insulin resistance, and reduced nitric oxide production precede the onset of peripheral insulin resistance," Arteriosclerosis, Thrombosis, and Vascular Biology, vol. 28, no. 11, pp. 1982-1988, 2008.

[173] E. Yamamoto, T. Nakamura, K. Kataoka et al., "Nifedipine prevents vascular endothelial dysfunction in a mouse model of obesity and type 2 diabetes, by improving eNOS dysfunction and dephosphorylation," Biochemical and Biophysical Research Communications, vol. 403, no. 3-4, pp. 258-263, 2010.

[174] T. B. Nascimento, R. D. Baptista, P. C. Pereira et al., "Vascular alterations in high-fat diet-obese rats: role of Endothelial Larginine/NO Pathway," Arquivos Brasileiros de Cardiologia, vol. 97, no. 1, pp. 40-45, 2011. 
[175] M. J. Zhu, M. Du, P. W. Nathanielsz, and S. P. Ford, "Maternal obesity up-regulates inflammatory signaling pathways and enhances cytokine expression in the mid-gestation sheep placenta," Placenta, vol. 31, no. 5, pp. 387-391, 2010.

[176] P. Singla, A. Bardoloi, and A. A. Parkash, "Metabolic effects of obesity: a review," World Journal of Diabetes, vol. 1, pp. 76$88,2010$.

[177] F. von Versen-Höynck, A. Rajakumar, M. S. Parrott, and R. W. Powers, "Leptin affects system a amino acid transport activity in the human placenta: evidence for STAT3 dependent mechanisms," Placenta, vol. 30, no. 4, pp. 361-367, 2009.

[178] D. M. Farley, J. Choi, D. J. Dudley et al., "Placental amino acid transport and placental leptin resistance in pregnancies complicated by maternal obesity," Placenta, vol. 31, no. 8, pp. 718-724, 2010.

[179] K. Fujita, K. Wada, Y. Nozaki et al., "Serum nitric oxide metabolite as a biomarker of visceral fat accumulation: clinical significance of measurement for nitrate/nitrite," Medical Science Monitor, vol. 17, no. 3, pp. 123-131, 2011.

[180] L. Rong-Na, Z. Xiang-Jun, C. Yu-Han, L. Ling-Qiao, and H. Gang, "Interaction between hydrogen sulfide and nitric oxide on cardiac protection in rats with metabolic syndrome," Zhongguo Yi Xue Ke Xue Yuan Xue Bao, vol. 33, no. 1, pp. 25-32, 2011.

[181] R. S. Miller, D. Diaczok, and D. W. Cooke, "Repression of GLUT4 expression by the endoplasmic reticulum stress response in 3T3-L1 adipocytes," Biochemical and Biophysical Research Communications, vol. 362, no. 1, pp. 188-192, 2007.

[182] N. Shen, X. Yu, F. Y. Pan, X. Gao, B. Xue, and C. J. Li, "An early response transcription factor, Egr-1, enhances insulin resistance in type 2 diabetes with chronic hyperinsulinism," Journal of Biological Chemistry, vol. 286, no. 16, pp. 1450814515, 2011.

[183] P. M. Catalano, "Obesity and pregnancy-the propagation of a viscous cycle?" Journal of Clinical Endocrinology and Metabolism, vol. 88, no. 8, pp. 3505-3506, 2003.

[184] G. C. Curhan, W. C. Willett, E. B. Rimm, D. Spiegelman, A. L. Ascherio, and M. J. Stampfer, "Birth weight and adult hypertension, diabetes mellitus, and obesity in US men," Circulation, vol. 94, no. 12, pp. 3246-3250, 1996.

[185] E. Oken, S. L. Rifas-Shiman, A. E. Field, A. L. Frazier, and M. W. Gillman, "Maternal gestational weight gain and offspring weight in adolescence," Obstetrics and Gynecology, vol. 112, no. 5, pp. 999-1006, 2008.

[186] B. H. Wrotniak, J. Shults, S. Butts, and N. Stettler, "Gestational weight gain and risk of overweight in the offspring at age $7 \mathrm{y}$ in a multicenter, multiethnic cohort study," American Journal of Clinical Nutrition, vol. 87, no. 6, pp. 1818-1824, 2008.

[187] E. Oken, E. M. Taveras, K. P. Kleinman, J. W. Rich-Edwards, and M. W. Gillman, "Gestational weight gain and child adiposity at age 3 years," American Journal of Obstetrics and Gynecology, vol. 196, no. 4, pp. 322.e1-322.e8, 2007.

[188] E. Oken and M. W. Gillman, "Fetal origins of obesity," Obesity Research, vol. 11, no. 4, pp. 496-506, 2003.

[189] G. Dorner and A. Plagemann, "Perinatal hyperinsulinism as possible predisposing factor for diabetes mellitus, obesity and enhanced cardiovascular risk in later life," Hormone and Metabolic Research, vol. 26, no. 5, pp. 213-221, 1994.

[190] A. Fraser, K. Tilling, C. MacDonald-Wallis et al., "Association of maternal weight gain in pregnancy with offspring obesity and metabolic and vascular traits in childhood," Circulation, vol. 121, no. 23, pp. 2557-2564, 2010.
[191] B. M. Margetts, M. G. Rowland, F. A. Foord, A. M. Cruddas, T. J. Cole, and D. J. Barker, "The relation of maternal weight to the blood pressures of Gambian children," International Journal of Epidemiology, vol. 20, no. 4, pp. 938-943, 1991.

[192] K. M. Godfrey, T. Forrester, D. J. Barker et al., "Maternal nutritional status in pregnancy and blood pressure in childhood," British Journal of Obstetrics and Gynaecology, vol. 101, no. 5, pp. 398-403, 1994.

[193] A. Laor, D. K. Stevenson, J. Shemer, R. Gale, and D. S. Seidman, "Size at birth, maternal nutritional status in pregnancy, and blood pressure at age 17: population based analysis," British Medical Journal, vol. 315, no. 7106, pp. 449453, 1997.

[194] P. M. Clark, C. Atton, C. M. Law, A. Shiell, K. Godfrey, and D. J. Barker, "Weight gain in pregnancy, triceps skinfold thickness, and blood pressure, in offspring," Obstetrics and Gynecology, vol. 91, no. 1, pp. 103-107, 1998.

[195] A. A. Mamun, M. O’Callaghan, L. Callaway, G. Williams, J. Najman, and D. A. Lawlor, "Associations of gestational weight gain with offspring body mass index and blood pressure at 21 years of ageevidence from a birth cohort study," Circulation, vol. 119, no. 13, pp. 1720-1727, 2009.

[196] M. F. Sewell, L. Huston-Presley, D. M. Super, and P. Catalano, "Increased neonatal fat mass, not lean body mass, is associated with maternal obesity," American Journal of Obstetrics and Gynecology, vol. 195, no. 4, pp. 1100-1103, 2006.

[197] B. E. Metzger, B. L. Silverman, N. Freinkel, S. L. Dooley, E. S. Ogata, and O. C. Green, "Amniotic fluid insulin concentration as a predictor of obesity," Archives of Disease in Childhood, vol. 65, no. 10, pp. 1050-1052, 1990.

[198] M. W. Gillman, S. Rifas-Shiman, C. S. Berkey, A. E. Field, and G. A. Colditz, "Maternal gestational diabetes, birth weight, and adolescent obesity," Pediatrics, vol. 111, no. 3, pp. 221226, 2003.

[199] D. Dabelea, "The predisposition to obesity and diabetes in offspring of diabetic mothers," Diabetes Care, vol. 30, supplement 2, pp. S169-S174, 2007.

[200] D. Dabelea, R. L. Hanson, P. H. Bennett, J. Roumain, W. C. Knowler, and D. J. Pettitt, "Increasing prevalence of type II diabetes in American Indian children," Diabetologia, vol. 41, no. 8, pp. 904-910, 1998.

[201] D. Dabelea, W. C. Knowler, and D. J. Pettitt, "Effect of diabetes in pregnancy on offspring: follow-up research in the Pima Indians," Journal of Maternal-Fetal and Neonatal Medicine, vol. 9, no. 1, pp. 83-88, 2000.

[202] T. D. Clausen, E. R. Mathiesen, T. Hansen et al., "High prevalence of type 2 diabetes and pre-diabetes in adult offspring of women with gestational diabetes mellitus or type 1 diabetes: the role of intrauterine hyperglycemia," Diabetes Care, vol. 31, no. 2, pp. 340-346, 2008.

[203] D. J. Pettitt and W. C. Knowler, "Long-term effects of the intrauterine environment, birth weight, and breast-feeding in Pima Indians," Diabetes Care, vol. 21, supplement 2, pp. B138-B141, 1998.

[204] Y. Yogev and G. H. Visser, "Obesity, gestational diabetes and pregnancy outcome," Seminars in Fetal and Neonatal Medicine, vol. 14, no. 2, pp. 77-84, 2009.

[205] L. Schack-Nielsen, K. F. Michaelsen, M. Gamborg, E. L. Mortensen, and T. I. Sørensen, "Gestational weight gain in relation to offspring body mass index and obesity from infancy through adulthood," International Journal of Obesity, vol. 34, no. 1, pp. 67-74, 2010. 
[206] J. A. Armitage, L. Poston, and P. D. Taylor, "Developmental origins of obesity and the metabolic syndrome: the role of maternal obesity," Frontiers of Hormone Research, vol. 36, pp. 73-84, 2008.

[207] T. A. Hillier, K. L. Pedula, M. M. Schmidt, J. A. Mullen, M. A. Charles, and D. J. Pettitt, "Childhood obesity and metabolic imprinting: the ongoing effects of maternal hyperglycemia," Diabetes Care, vol. 30, no. 9, pp. 2287-2292, 2007.

[208] M. W. Gillman, H. Oakey, P. A. Baghurst, R. E. Volkmer, J. S. Robinson, and C. A. Crowther, "Effect of treatment of gestational diabetes mellitus on obesity in the next generation," Diabetes Care, vol. 33, no. 5, pp. 964-968, 2010.

[209] I. Rogers, "The influence of birthweight and intrauterine environment on adiposity and fat distribution in later life," International Journal of Obesity, vol. 27, no. 7, pp. 755-777, 2003.

[210] M. A. Charles, D. J. Pettitt, R. L. Hanson et al., "Familial and metabolic factors related to blood pressure in Pima Indian children," American Journal of Epidemiology, vol. 140, no. 2, pp. 123-131, 1994.

[211] C. S. Wright, S. L. Rifas-Shiman, J. W. Rich-Edwards, E. M. Taveras, M. W. Gillman, and E. Oken, "Intrauterine exposure to gestational diabetes, child adiposity, and blood pressure," American Journal of Hypertension, vol. 22, no. 2, pp. 215-220, 2009.

[212] E. P. Gunderson, C. P. Quesenberry, D. R. Jacobs, J. Feng, C. E. Lewis, and S. Sidney, "Longitudinal study of prepregnancy cardiometabolic risk factors and subsequent risk of gestational diabetes mellitus: the CARDIA study," American Journal of Epidemiology, vol. 172, no. 10, pp. 1131-1143, 2010.

[213] C. R. Assumpção, T. M. Brunini, N. R. Pereira et al., "Insulin resistance in obesity and metabolic syndrome: is there a connection with platelet l-arginine transport?" Blood Cells, Molecules, and Diseases, vol. 45, no. 4, pp. 338-342, 2010.

[214] K. Kikuta, T. Sawamura, S. Miwa, N. Hashimoto, and T. Masaki, "High-affinity arginine transport of bovine aortic endothelial cells is impaired by lysophosphatidylcholine," Circulation Research, vol. 83, no. 11, pp. 1088-1096, 1998.

[215] K. Posch, S. Simecek, T. C. Wascher et al., "Glycated lowdensity lipoprotein attenuates shear stress-induced nitric oxide synthesis by inhibition of shear stress-activated Larginine uptake in endothelial cells," Diabetes, vol. 48, no. 6, pp. 1331-1337, 1999.

[216] M. T. Jay, S. Chirico, R. C. Siow et al., "Modulation of vascular tone by low density lipoproteins: effects on Larginine transport and nitric oxide synthesis," Experimental Physiology, vol. 82, no. 2, pp. 349-360, 1997.

[217] A. Nuszkowski, R. Gräbner, G. Marsche, A. Unbehaun, E. Malle, and R. Heller, "Hypochlorite-modified low density lipoprotein inhibits nitric oxide synthesis in endothelial cells via an intracellular dislocalization of endothelial nitric-oxide synthase," Journal of Biological Chemistry, vol. 276, no. 17, pp. 14212-14221, 2001.

[218] W. G. Rossmanith, U. Hoffmeister, S. Wolfahrt et al., "Expression and functional analysis of endothelial nitric oxide synthase (eNOS) in human placenta," Molecular Human Reproduction, vol. 5, no. 5, pp. 487-494, 1999.

[219] J. Ketonen, T. Pilvi, and E. Mervaala, "Caloric restriction reverses high-fat diet-induced endothelial dysfunction and vascular superoxide production in C57Bl/6 mice," Heart and Vessels, vol. 25, no. 3, pp. 254-262, 2010.

[220] S. Kagota, E. Chia, and J. J. McGuire, "Preserved arterial vasodilation via endothelial protease-activated receptor-2 in obese type 2 diabetic mice," British Journal of Pharmacology, vol. 164, no. 2, pp. 358-371, 2011.

[221] S. Fatani, I. Itua, P. Clark, C. Wong, and E. K. Naderali, "The effects of diet-induced obesity on hepatocyte insulin signaling pathways and induction of non-alcoholic liver damage," International Journal of General Medicine, vol. 4, pp. 211-219, 2011.

[222] J. L. Di Iulio, N. M. Gude, R. G. King, C. G. Li, M. J. Rand, and S. P. Brennecke, "Human placental nitric oxide synthase activity is not altered in diabetes," Clinical Science, vol. 97, no. 1, pp. 123-128, 1999.

[223] H. B. Eccleston, K. K. Andringa, A. M. Betancourt et al., "Chronic exposure to a high-fat diet induces hepatic steatosis, impairs nitric oxide bioavailability, and modifies the mitochondrial proteome in mice," Antioxidants and Redox Signaling, vol. 15, no. 2, pp. 447-459, 2011.

[224] P. M. Catalano and S. Hauguel-De Mouzon, "Is it time to revisit the Pedersen hypothesis in the face of the obesity epidemic?" American Journal of Obstetrics and Gynecology, vol. 204, no. 6, pp. 479-487, 2011.

[225] J. Pedersen, Diabetes and pregnancy: blood sugar of newborn infants, Ph.D. thesis, Danish Science Press, Copenhagen, Denmark, 1952.

[226] T. W. Leung and T. T. Lao, "Placental size and large-forgestational-age infants in women with abnormal glucose tolerance in pregnancy," Diabetic Medicine, vol. 17, no. 1, pp. 48-52, 2000.

[227] S. Hauguel-de Mouzon, J. Lepercq, and P. Catalano, "The known and unknown of leptin in pregnancy," American Journal of Obstetrics and Gynecology, vol. 194, no. 6, pp. 1537$1545,2006$.

[228] J. T. Smith and B. J. Waddell, "Leptin distribution and metabolism in the pregnant rat: transplacental leptin passage increases in late gestation but is reduced by excess glucocorticoids," Endocrinology, vol. 144, no. 7, pp. 3024-3030, 2003.

[229] F. M. Stewart, D. J. Freeman, J. E. Ramsay, I. A. Greer, M. Caslake, and W. R. Ferrell, "Longitudinal assessment of maternal endothelial function and markers of inflammation and placental function throughout pregnancy in lean and obese mothers," Journal of Clinical Endocrinology and Metabolism, vol. 92, no. 3, pp. 969-975, 2007.

[230] D. J. Tuffnell, J. West, and S. A. Walkinshaw, "Treatments for gestational diabetes and impaired glucose tolerance in pregnancy," Cochrane Database of Systematic Reviews, no. 3, Article ID CD003395, 2003.

[231] C. A. Crowther, J. E. Hiller, J. R. Moss, A. J. McPhee, W. S. Jeffries, and J. S. Robinson, "Effect of treatment of gestational diabetes mellitus on pregnancy outcomes," New England Journal of Medicine, vol. 352, no. 24, pp. 2477-2486, 2005.

[232] A. Burguet, "Long term outcome in children of mothers with gestational diabetes," Journal de Gynecologie Obstetrique et Biologie de la Reproduction, vol. 39, no. 8, supplement 2, pp. S322-S337, 2010. 


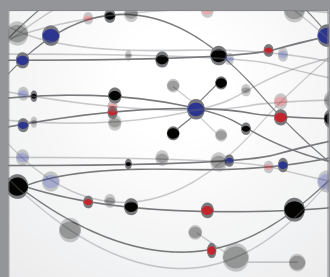

The Scientific World Journal
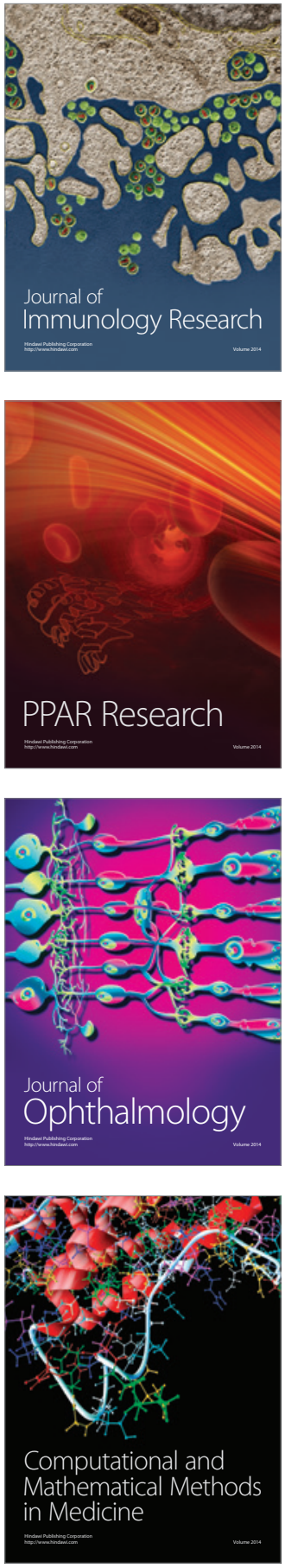

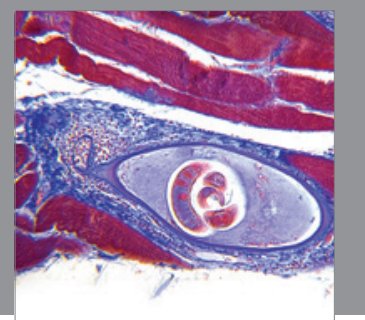

Gastroenterology

Research and Practice
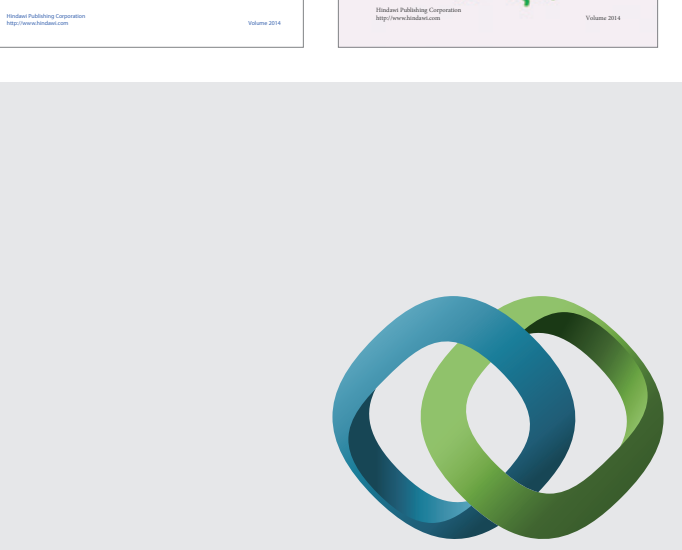

\section{Hindawi}

Submit your manuscripts at

http://www.hindawi.com
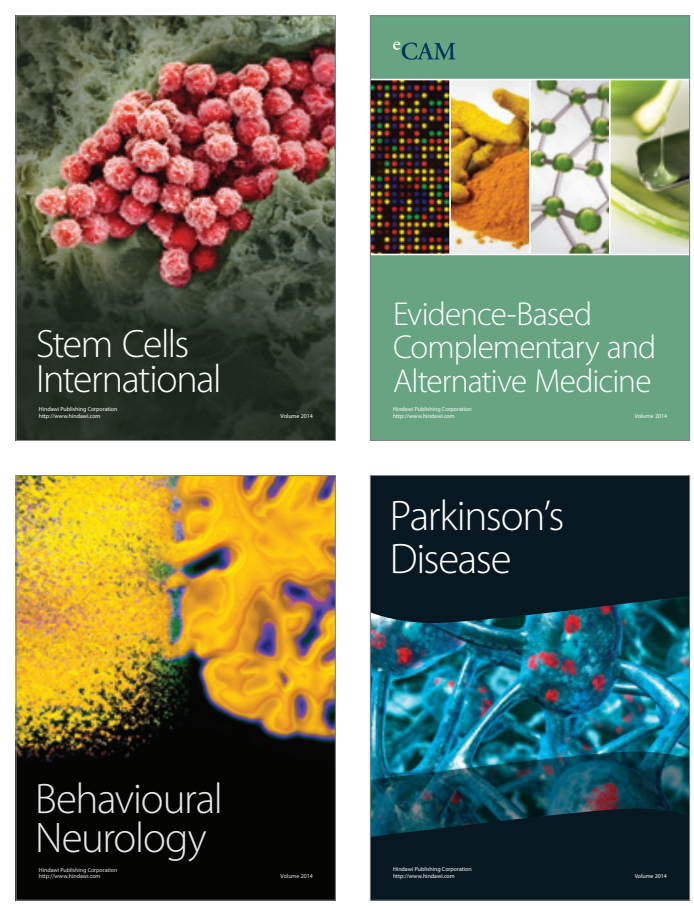

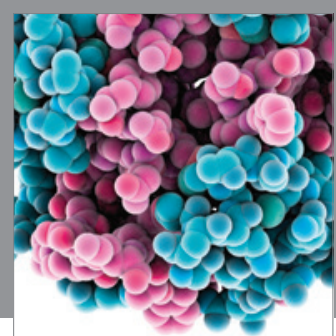

Journal of
Diabetes Research

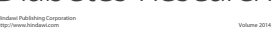

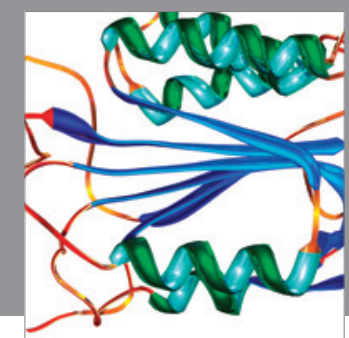

Disease Markers
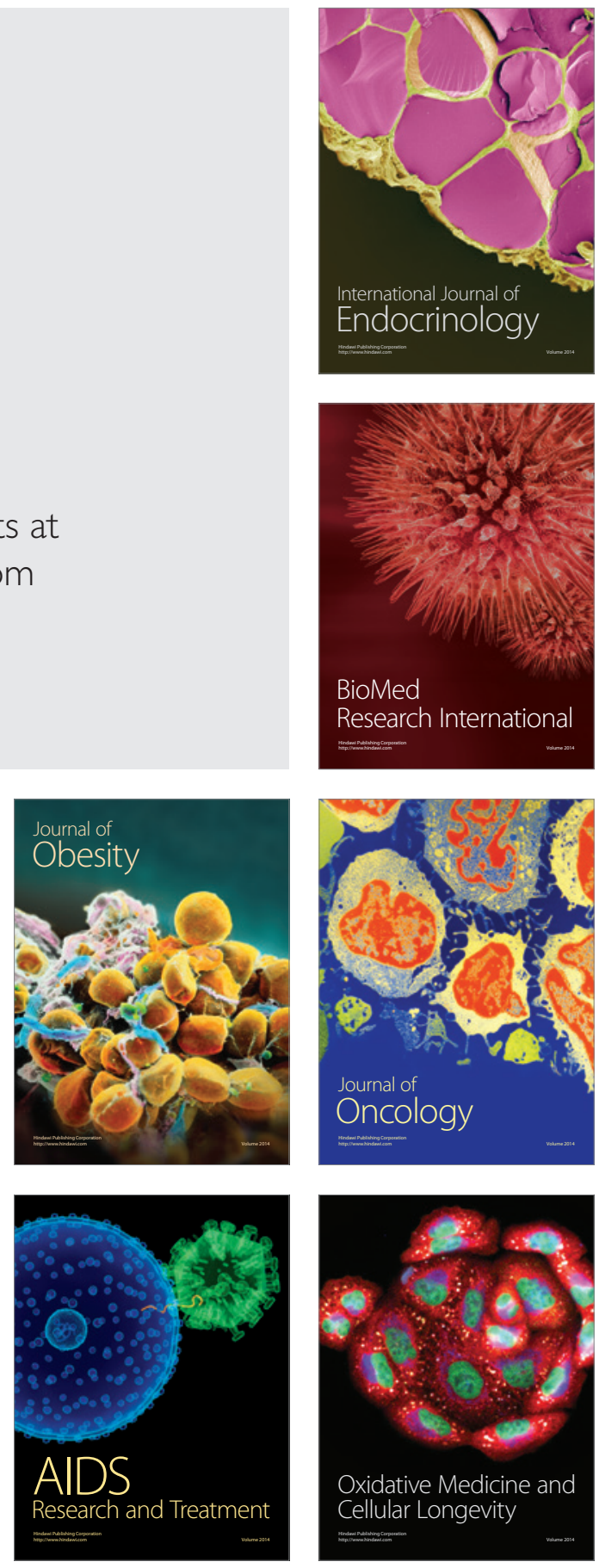